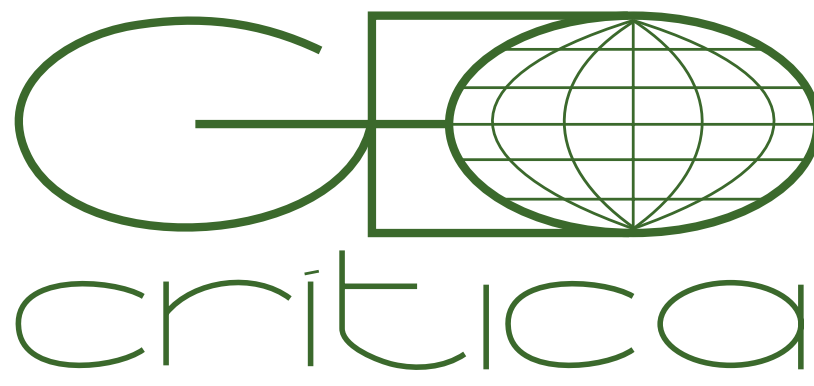

Scripta Nova

Revista Electrónica de Geografía y Ciencias Sociales Universitat de Barcelona

ISSN: $1138-97$

Vol. XXIII. Núm. 609

1 de marzo de 2019

\title{
EL NUEVO PARADIGMA DE LAS MIGRACIONES INTERNAS EN ESPAÑA: MIGRANTES URBANOS, MÁS MÓVILES Y CUALIFICADOS. EL CASO DE CASTILLA Y LEÓN
}

\author{
Miguel González-Leonardo \\ Centre d'Estudis Demogràfics / Departament de Geografia (UAB) \\ mgonzalez@ced.uab.es
}

Este trabajo se

ha realizado en el marco del Programa de Doctorado en Demografía del Centro de Estudios Demográficos y el Departamento de Geografía de la Universidad Autónoma de Barcelona, dentro de los proyectos: "Comportamientos demográficos y estrategias residenciales: apuntes para el desarrollo de nuevas políticas sociales" (CSO2016-79142-R) del Ministerio de Economía y Competitividad;

"Movilidad residencial, selección sociodemográfica y substitución de la población: ¿hacia la polarización de las ciudades españolas?" MOVIPOL (CSO2014-60967JIN) del Ministerio de Economía y Competitividad y del Programa CERCA / Generalitat de Catalunya.

\author{
Antonio López-Gay \\ Centre d'Estudis Demogràfics \\ tlopez@ced.uab.es
}

Recibido: 27 de febrero de 2018; Devuelto para correcciones: 22 de mayo de 2018; Aceptado: 14 de julio de 2018

\begin{abstract}
EL nuevo paradigma de las migraciones internas en España: migrantes urbanos, más móviles y cualificados. El caso de Castilla y León (Resumen)
\end{abstract}

Tras décadas de relativa calma migratoria, la emigración, tanto la interregional como la internacional, se ha incrementado en las comunidades autónomas que tradicionalmente han sido expulsoras. A diferencia de etapas anteriores, cuando los emigrantes estaban escasamente formados y partían de ámbitos rurales, los actuales flujos de salida tienen un nivel de instrucción elevado y abandonan las ciudades de sus respectivas regiones. Castilla y León es un claro ejemplo de esta dinámica: se trata de la región con más jóvenes emigrados, un colectivo que presenta un nivel de instrucción elevado..

Palabras clave: Castilla y León, migraciones internas, talento, perfil de los migrantes, segregación residencial.

\section{The new paradigm of internal migration in Spain: more mobile, urban and skilled migrants. The case of Castile and León (Abstract) \\ After decades of low levels of out-migration, internal and international out-flows have increased in the same Spanish areas that experienced large population losses due to migration during most of the XXth century. But, unlike previous periods, the current mi- grants are highly educated and are moving out of urban areas. Castile and León is a clear example of this dynamic: it is the region with the largest proportion of young adults living outside their region of birth, a trend driven by the highly educated groups.}

Key words: Castile and León, internal migration, talent, migratory profiles, residential segregation. 
Entre mediados de los años 70 y la primera mitad de los 90, se registró un descenso de la movilidad asociada al factor trabajo en España, que siguió a las grandes oleadas migratorias de la etapa desarrollistaํ. Desde finales de la década de 1990, principalmente entrado el siglo XXI, España se convirtió en un país de inmigración exterior ${ }^{2}$ y se incrementó la movilidad interior de corta, media y larga distancia, tanto para la población nacional como para los residentes alóctonos 3 . Con la recesión económica iniciada en 2008, los flujos procedentes del extranjero se redujeron y una parte de los inmigrantes llegados a nuestro país retornaron o se marcharon hacia terceros países. En el trascurso de esta última etapa recesiva, se ha observado un incremento de la emigración entre la población autóctona, hacia el exterior ${ }^{4}$ y desde las CC. AA. menos dinámicas hacia las regiones españolas más pujantes ${ }^{5}$. La citada dinámica de la población autóctona contrasta con los patrones observados hasta el momento, cuya tendencia durante las fases recesivas de la economía había sido la contracción de los flujos migratorios ${ }^{6}$.

El primer objetivo de este artículo se centra en cuantificar el aumento de la movilidad interregional y exterior entre la población autóctona a lo largo del siglo XXI, estudiando el caso de Castilla y León, una región tradicionalmente expulsora. Actualmente, los jóvenes castellanos y leoneses constituyen el colectivo más numeroso, en términos relativos y en comparación con el resto de comunidades autónomas españolas, de residentes fuera de su región de nacimiento. En una primera toma de contacto con los datos de la Estadística de Variaciones Residenciales (EVR) se aprecia que la salida de emigrantes nacidos en la región ha aumentado, así como las pérdidas por saldo migratorio. Una primera hipótesis de partida apuntaría al incremento de la movilidad entre la población activa joven, ahora las cohortes vacías, principalmente en lo que a las salidas se refiere. La mayor parte de los movimientos migratorios de efectivos españoles son interiores, pero se sospecha que la emigración exterior también ha ganado peso, a pesar de que continúa siendo minoritaria.

El segundo objetivo es la caracterización del perfil de los actuales emigrantes, haciendo una comparación con los migrantes de etapas anteriores. La hipótesis de partida se sostiene en varios argumentos diferenciales, que son percibidos a nivel social pero que no han sido medidos ni cuantificados hasta ahora:

(i) El ámbito de procedencia de los emigrantes, con un peso creciente de las ciudades como lugares de partida, en detrimento de las áreas rurales, tanto de manera absoluta como de forma relativa la población residente.

\footnotetext{
1 Recaño, 2004-a y 2006; Franch, 2009.

2 Arango, 2015; López de Lera, 2015; Domingo y Cabré, 2015; Galeano, 2016; Recaño, 2016.

3 Recaño, 2004-b, 2006 y 2016; García-Coll, 2005; Ródenas y Martí, 2005; Cámara, 2009.

4 González-Laxe, Martín-Bermúdez y Martín-Palmero, 2013; Herrera-Ceballos, 2014; Rubio-Castillo, 2014; Artal, Navarro y Requena, 2015.

5 González-Laxe, Martín-Bermúdez y Martín-Palmero, 2013; González Leonardo, 2017.

6 Recaño y Cabré, 2003.
} 
(i) El aumento del nivel educativo de este colectivo, con un elevado nivel de instrucción, frente al escaso nivel formativo de los antiguos migrantes.

(iii) Un perfil profesional cualificado, que contrasta con las ocupaciones industriales y elementales de sus predecesores.

(iv) La hegemonía de las dos ciudades globales españolas, Madrid y Barcelona, como principales focos receptores y la pérdida de capacidad de atracción del País Vasco, junto a la dispersión de los destinos secundarios.

(v) Unos patrones de localización urbana completamente distintos, con una marcada concentración residencial en los sectores de clase media-acomodada, en comparación a los barrios de clase trabajadora donde residen los emigrados más longevos.

Castilla y León es especialmente interesante para el presente estudio, no solo por ser la región española más emigratoria en la actualidad, sino porque el colectivo emigrado presenta el nivel de instrucción más alto del conjunto nacional7

\section{Las migraciones internas en España y la peculiaridad de Castilla y León como región emigratoria}

Las migraciones internas en España, a grandes rasgos, han seguido una evolución similar respecto a la mayoría de países avanzados, aunque con un notable retraso en el calendario y unas características propias ${ }^{8}$. La trayectoria de la dinámica migratoria se desarrolla de forma similar a los estados europeos de industrialización tardía, como Italia o Portugal ${ }^{9}$. En la actualidad, nadie afirmaría que las sociedades preindustriales eran inmóviles; sin embargo, la Revolución Industrial, que ha tenido lugar en el hemisferio septentrional principalmente durante los siglos XIX y XX, así como la integración de las economías a escala mundial, trasformaron el modelo migratorio, intensificando los desplazamientos y aumentando la distancia recorrida ${ }^{10}$. La mayor parte de los movimientos migratorios preindustriales se caracterizaban por ser desplazamientos de corta distancia, tanto campo-ciudad ${ }^{11}$ como intrarurales $^{12}$.

En torno a 1860, podríamos hablar de una salida continua y más o menos intensa de la población rural en España ${ }^{13}$. El desarrollo industrial de algunos enclaves urbanos españoles, junto a la sobrepoblación de los campos, generaron un éxodo rural nada desdeñable ${ }^{14}$. En un primer momento, los flujos migratorios se dirigían hacia las ciudades de la propia provincia o región ${ }^{15}$, pero posteriormente se incrementaron

7 González-Leonardo y López-Gay, 2019.

8 García Barbancho, 1967.

9 Silvestre, 2002.

10 Silvestre, 2002.

11 Reher, 1990.

12 Florencio y López-Martínez, 2000.

13 Silvestre, 2002; Erdozáin y Mikelarena, 1996.

14 Silvestre, 2002.

15 García Barbancho, 1967; Arango, 1976; Vidal, 1979; Silvestre, 2002. 
los movimientos y la distancia recorrida. La mayor parte de las urbes de la Península Ibérica, a excepción de Madrid, Barcelona y Bilbao, no podían proporcionar empleos suficientes para cubrir la demanda laboral de trabajadores provenientes de medio rural de su propia provincia y de territorios limítrofes, generando algunos movimientos interiores de larga distancia hacia dichas ciudades y flujos de salida de carácter transoceánico ${ }^{16}$.

Durante los tres primeros decenios del siglo XX, principalmente entre mediados de la década de 1910 y principios de los años 30, se produce un aumento de las migraciones internas de media y larga distancia y un descenso de la emigración exterior. El detonante de esta corriente sería, por un lado, el incremento de la producción industrial ligado a la Primera Guerra Mundial y a la posterior etapa de bonanza económica global, pero también se debe a una demanda creciente de trabajadores para diversas obras públicas en determinadas ciudades, como el metro ${ }^{17}$. A lo largo de estos años, también se intensifica el desarrollo industrial en algunas urbes medianas, como Valladolid, donde aumenta la entidad de las actividades secundarias que tuvieron su génesis con la llegada del ferrocarril en segunda mitad del XIX ${ }^{18}$. En el trascurso del citado periodo, un contingente importante de población rural castellana emigra hacia las ciudades de la región, los principales focos industriales españoles y, en menor medida, en dirección a Argentina, Cuba y Venezuela. No obstante, el abundante balance natural compensó el saldo migratorio negativo. Las provincias castellanas y leoneses, a excepción de las occidentales, León, Zamora y Salamanca, se vieron poco afectadas por las migraciones ultramarinas ${ }^{19}$.

Entre 1931 y principios de los años 50, se produce un descenso en los movimientos migratorios interiores, en un primer momento causado por la Crisis de 1929, que llega a España con cierto retraso, pero fundamentalmente por la Guerra Civil y la posterior etapa de Autarquía ${ }^{20}$. Algunos autores afirman que el inicio de las grandes corrientes migratorias queda truncado por la crisis, el conflicto bélico y la posguerra ${ }^{21}$.

Durante la etapa desarrollista de la economía española, entre mediados de los 50 y la primera mitad de los 70, los movimientos migratorios alcanzaron una envergadura sin precedentes y modificaron por completo la distribución territorial de la población. Se produjo un fuerte éxodo rural que supuso el despoblamiento de la mayor parte del territorio y la concentración de personas en sectores determinados ${ }^{22}$ : los grandes polos económicos - Madrid, Barcelona y País Vasco- y, en menor medida, en Valencia, Sevilla y algunas ciudades medias, como Zaragoza, Valladolid o Santa Cruz de Tenerife ${ }^{23}$. En esta etapa dominan los movimientos

16 Arango, 1976.

17 Tatjer, 1995; López-Gay, 2007; Franch, 2009.

18 Caballero, Delgado y Martínez, 2012.

19 García Zarza, 1983; Caballero, Delgado y Martínez, 2012.

20 García Barbancho, 1967; Vidal, 1979; Silvestre, 2002; Franch, 2009.

21 García Barbancho, 1967.

22 Cabré, Moreno y Pujadas, 1985.

23 García Barbancho y Delgado Cabeza, 1988. 
interregionales ${ }^{24}$ y ha sido ampliamente estudiada en la literatura nacional sobre migraciones ${ }^{25}$ y también a escala autonómica para el conjunto de provincias que hoy componen Castilla y León ${ }^{26}$. En la región castellana y leonesa han sido especialmente adversas las consecuencias de las grandes oleadas emigratorias del periodo 1955-1975. La salida masiva de habitantes, a mayores de la consiguiente pérdida de activos jóvenes, tuvo consecuencias negativas sobre la nupcialidad -emigración diferencial por sexos- y los nacimientos ${ }^{27}$. Madrid es la gran beneficiaria de la emigración procedente de Castilla y León, gigantesca aglomeración que ha crecido a base de desertizar la corona de $300 \mathrm{Km}$ que la rodea, en especial las provincias limítrofes. No ha habido alternativa a la emigración castellana hacia Madrid, ante la ausencia de grandes centros urbanos en el interior de la Meseta, si se exceptúa la ciudad de Valladolid ${ }^{28}$.

Con posterioridad a la crisis del petróleo de 1973, los flujos migratorios pierden intensidad, son mucho más equilibrados y se difuminan las direcciones interprovinciales $^{29}$, con un peso relativamente destacado de las migraciones de retorno ${ }^{30}$, aunque no tuvieron la intensidad esperada. El País Vasco pierde su capacidad de atracción y se convierte en expulsor, mientras que las provincias de Barcelona y Madrid registran valores negativos en años concretos. Se produce una diversificación de los destinos, con un mayor protagonismo de los polos migratorios secundarios: el Litoral Mediterráneo, ambos archipiélagos, el Valle del Ebro, Andalucía y el sector septentrional de Castilla-La Mancha por la desconcentración de Madrid ${ }^{31}$. En Castilla y León, las corrientes de retorno, más reducidas en comparación a otras regiones de tradición emigratoria, no llegan a compensar la salida continuada de efectivos ${ }^{32}$, y mucho menos los desequilibrios en la estructura de población y el marcado envejecimiento regional; a pesar de que se produce un flujo de retornados destacable desde el País Vasco, no tanto desde Madrid u otras regiones receptoras ${ }^{33}$.

Entre mediados de los 70 y mitad de los años 90 existe una baja movilidad geográfica del factor trabajo en España, pese a las oscilaciones observadas en función de la coyuntura económica a lo largo del periodo, aumentando en las etapas de expansión y contrayéndose durante las fases recesivas ${ }^{34}$ : entre 1973 y mediados de los 80, la crisis

24 López-Gay, 2007; Franch, 2009.

25 García Barbancho, 1967; Arango, 1976; García Barbancho y Delgado Cabeza, 1988; Ródenas, 1994.

26 Pérez Díaz, 1971 y 1972; García Fernández, 1981; García Zarza, 1983; Caballero, Delgado y Martínez, 2012.

27 Del Rey y Cebrián, 2009.

28 Rapado, 1985.

29 Cabré, Moreno y Pujadas, 1985; García Barbancho y Delgado Cabeza, 1988; Olano, 1990; Ródenas, 1994; Pujadas y García-Coll, 1995; Recaño, 2004-b y 2006.

30 Pascual de Sans, 1983; Recaño, 2004-a, 2004-b y 2006.

31 García-Coll y Puyol, 1997; Recaño, 2004-b y 2006.

32 Recaño, 2004-a.

33 Rapado, 1985.

34 Recaño y Cabré, 2003; Recaño, 2004-a y 2006. 
económica y la reconversión industrial se traducen en una escasa movilidad; desde 1985 hasta 1991 se produce una etapa expansiva de la economía y una mayor intensidad migratoria, tanto a escala interprovincial como intraprovincial; en el periodo 1992-1995 se desarrolla una breve etapa recesiva, con la consiguiente reducción de los flujos.

Desde 1996 hasta 2008 se produce un nuevo aumento de la movilidad migratoria $^{35}$, que tiene su génesis en varias cuestiones. En primer lugar, se genera un fuerte incremento de las migraciones intraprovinciales, principalmente por los procesos de desconcentración urbana y suburbanización ${ }^{36}$. Continúan los retornos de antiguos emigrados ${ }^{37}$. Otro hito, y quizá el más relevante, es la llegada de población procedente del extranjero, que se intensifica entrado el siglo XXI y supone un factor determinante en el sistema migratorio español ${ }^{38}$. En 2009 la población nacida en el extranjero sumaba seis millones de residentes en el conjunto de España (13,1 \%) y 185.000 en Castilla y León $(7,3 \%$ ), que protagonizaron el $25 \%$ de los cambios de residencia entre 2001 y 2015 a escala nacional ${ }^{39}$ y en torno al 13 \% en el ámbito regional. En Castilla y León, la llegada de extranjeros fue más reducida, se produjo de forma tardía y se repartió de manera desigual por el territorio ${ }^{40}$. Por último, aunque ha sido poco estudiado y cuantificado, y no por ello menos importante, habría que considerar el aumento de los desplazamientos de media-larga distancia protagonizados por la población autóctona. Durante los primeros siete años del siglo XXI, las migraciones internas en España han aumentado en números absolutos, tanto para la población nacida en España como para los foráneos, incrementándose las tasas de la población autóctona, en términos relativos, por encima de las de los alóctonos, aunque continúan siendo más altas para los extranjeros ${ }^{41}$.

En los registros de la EVR entre 2009 y 2015 , el periodo de la reciente crisis económica, la llegada de extranjeros desde el exterior se reduce, aunque en los primeros años la caída no es tan acusada por la reagrupación familiar ${ }^{42}$. Este fenómeno se produce con cierto retraso en las CC. AA. de menos crecimiento demográfico ${ }^{43}$. Las migraciones internas de media y larga distancia de ese colectivo también se reducen ${ }^{44}$. La movilidad residencial cae, ahora son las cohortes vacías las demandantes de vivienda ${ }^{45}$. No obstante, los desplazamientos de media y larga distancia de la población activa joven nacida en España continúa incrementándose, tanto las salidas hacia el

35 Recaño, 2004-b y 2006; García, 2005; Ródenas y Martí, 2005; Cámara, 2009.

36 Feria y Susino, 2006; Módenes, 2006; López-Gay, 2007.

37 Recaño, 2004-a, 2004-b y 2006.

38 Reher y Requena, 2011; Arango, 2015; Domingo y Cabré, 2015; López de Lera, 2015; Galeano, 2016; Recaño, 2016.

39 Recaño, 2016.

40 Delgado y Martínez, 2016-a y 2016-b.

41 Cámara, 2009.

42 Domingo y Sabater, 2013; Domingo y Blanes, 2015.

43 Delgado y Martínez, 2016-a.

44 Recaño, 2016.

45 Módenes y López-Colás, 2014; López-Gay, 2016-b. 
exterior ${ }^{46}$ como los movimientos interiores entre regiones menos dinámica y áreas más productivas, descrito para el caso gallego ${ }^{47}$ y en Castilla y León ${ }^{48}$.

La reciente dinámica migratoria de la población autóctona contrasta con los patrones observados hasta el momento, cuando la tendencia ligada a las etapas de recesión económica era la contracción de los flujos. Durante la última crisis, el saldo migratorio de la población extranjera se tornó a signo negativo, y la salida de población nacida en España hacia el exterior y los intercambios entre regiones se han exacerbado. El protagonismo migratorio de la población extranjera ha relegado a un segundo plano los estudios sobre movilidad de población autóctona. Las migraciones encadenadas, "onward" podrían tener mucho que ver en el citado aumento de la movilidad ${ }^{49}$, consecuencia, entre otros factores, de la inestabilidad y temporalidad laboral ${ }^{50}$, acentuada durante la crisis.

Recaño ${ }^{51}$ muestra que las provincias interiores son las que presentan las tasas migratorias netas negativas más bajas, sobre todo las cercanas a Madrid, entre las que se incluye el territorio castellano y leonés. Mediante la aplicación de varios modelos de regresión logística, obtiene una mayor prevalencia hacia la movilidad interregional de los españoles en el Censo de 2011 respecto al de 2001. También refleja que Castilla y León es la región española con el coeficiente emigratorio más elevado. González Laxe, Martín Bermúdez y Martín Palmero ${ }^{52}$ perciben un incremento en los flujos de salida de la población gallega hacia otras parte de España y denominan este nuevo estadio como "la tercera etapa emigratoria", refiriendo que: "actualmente empiezan a conocerse datos de que a finales del siglo XX y principios del presente se vislumbra un fenómeno migratorio igual en esencia, pero distinto en el fondo: la economía gallega sigue expulsando recursos humanos hacia fuera de sus fronteras, pero resulta diferente porque en su inmensa mayoría (a diferencia de épocas anteriores en que la mano de obra estaba escasamente formada) ese flujo migratorio está formado en general por personas particularmente jóvenes, cada vez más cualificadas, y que emigran no ya a Europa y América, sino en su mayoría al resto de España. Este fenómeno, aunque percibido socialmente, está poco estudiado y cuantificado en la actualidad".

Como se verá durante el transcurso de la investigación, Madrid y, secundariamente, Barcelona, son los principales focos de atracción de los emigrantes castellanos y leoneses. En línea a la teoría del sistema mundial ${ }^{53}$, ambas ciudades globales concentran las actividades tecnológicas, financieras y los servicios avanzados, condiciones que fomentan la afluencia de inmigrantes y de población cualificada ${ }^{54}$. Dentro de

46 González-Ferrer, 2013; Herrera-Ceballos, 2014; Rubio-Castillo, 2014; Artal, Navarro y Requena, 2015.

47 González-Laxe, Martín-Bermúdez y Martín-Palmero, 2013.

48 González-Leonardo, 2017.

49 Ródenas y Martí, 2006.

50 Recaño, 2006.

512014.

522013.

53 Portes y Walton, 1981; Wallerstein, 1974; Sassen, 1993.

54 Sassen, 1993. 
estas urbes existe una marcada segregación urbana y unas preferencias residenciales evidentes en función de la situación socioeconómica, el nivel de instrucción y la etapa del ciclo de vida residencial ${ }^{55}$. La centralidad urbana es el patrón de localización más común entre los inmigrantes más educados ${ }^{56}$. En la elección del destino, tanto en las migraciones de media y larga distancia como en la movilidad residencial, entran en juego lo que algunos autores denominan como factores duros, "hard factors" -oportunidades de trabajo, salarios, redes personales- y factores blandos, "soft factors" - oferta de ocio y cultura, comodidades, ambiente ${ }^{57}$. Florida ${ }^{58}$ otorga un papel predominante a las condiciones blandas en la elección de destino por parte de la "clase creativa", mientras que la literatura apunta que los factores duros suelen tener un peso más destacado en la mayor parte de movimientos migratorios ${ }^{59}$, con un protagonismo destacado del empleo ${ }^{60}$ y las redes personales ${ }^{61}$. A menudo, las condiciones blandas juegan un papel secundario o complementario a los factores duros ${ }^{62}$.

\section{Fuentes y método}

Se ha seguido una metodología de tipo cuantitativo, a partir de los microdatos de diversas fuentes del Instituto Nacional de Estadística y tablas agregadas de Anuarios Estadísticos anteriores a 1987. Se ha trabajado con la Estadística de Variaciones Residenciales entre los años 1988 y 2015 y con las cifras de migraciones de los Anuarios Estadísticos del INE del periodo 1962-1987. En cuanto a las fuentes de stock, se ha seleccionado información de los Censos de Población de 1981, 1991, 2001 y 2011 y del Padrón Municipal de Habitantes de 2016.

Para conocer los flujos y saldos migratorios se han utilizado los referidos microdatos de la EVR entre 1988 y 2015, teniendo en cuenta las salidas y entradas de Castilla y León allende los límites regionales. Con el fin de conseguir una serie temporal más larga, desde 1962, se ha incluido la información referente a migraciones de los Anuarios Estadísticos mencionado. Esta fuente proporciona información de migración interna y exterior, aunque para la inmigración desde otros países solo hay datos disponibles desde 1982. Por otra parte, hay que considerar ciertas limitaciones de la EVR, como el subregistro: muchas personas no se empadronan cuando realizan un movimiento migratorio y, por lo tanto, la movilidad siempre será mayor respecto los resultados que arrojan las cifras. También existe cierto desfase a la hora de coordinar las altas y bajas padronales, más importante en el periodo anterior a 1988. Entre 1988 y 2015 se han seleccionado los movimientos migratorios por naturaleza, nacidos en

55 Leal, 2002; Hamnett, 2003; Domingo y Bayona, 2004; López-Gay, 2006, 2007, 2016-a y 2016-b; Leal y Domínguez, 2008.

56 López-Gay, 2016-a.

57 Florida, 2002; Sleutjes and Roterman, 2014.

582002.

59 Brown and Meczynski, 2009; Martin-Brelot y otros, 2010; Miguelez y Moreno, 2014.

60 Hansen and Niedomysl, 2009; Buch y otros, 2014.

61 Musterd and Murie, 2010.

62 Hansen and Niedomysl, 2009. 
Castilla y León, en el extranjero y en otras regiones españolas. Desde 1988 hasta 2001 no hay registros sobre emigración exterior desglosados por lugar de nacimiento, aunque las salidas hacia el extranjero fueron prácticamente residuales en este periodo. Finalmente, se han obtenido las tasas de emigración, inmigración y migración neta de la población autóctona, por sexo y grupos de edad quinquenales para tres periodos: 1991-2000, 2001-2008 y 2009-2015. La EVR también se ha utilizado en el entre los años 1988 y 2015 para estimar el ámbito de procedencia de los emigrados autóctonos entre 25 y 39 años: municipios menores de 2.000 habitantes, 2.000-5.000, 5.001-10.000, no capitales $>10.000$, áreas de influencia urbana (catalogación del Atlas Estadístico de las Áreas Urbanas del Ministerio de Fomento) y capitales de provincia.

Tasa de emigración por edad: $\mathrm{TE}_{\mathrm{x}}=\frac{E_{x}^{t+n}}{\left(\frac{P_{x}^{t}+P_{x}^{t+n}}{2}\right)} * 1.000$

$E_{x}^{t+n}$ : emigrantes a la edad x en el periodo $\mathrm{t}+\mathrm{n}$.

$P_{x}^{t}$ : población al inicio del periodo.

$P_{x}^{t+n}$ : población al final del periodo.

Tasa de inmigración por edad: $T I_{x}=\frac{I_{x}^{t+n}}{\left(\frac{P_{x}^{t}+P_{x}^{t+n}}{2}\right)} * 1.000$

$I_{x}^{t+n}$ : inmigrantes a la edad $x$ en el periodo $t+n$.

$P_{x}^{t}$ : población al inicio del periodo.

$P_{x}^{t+n}$ : población al final del periodo.

Tasa de migración neta por edad: $T M N_{x}=\frac{I_{x}^{t}-E_{x}^{t}}{\left(\frac{P_{x}^{t}+P_{x}^{t+n}}{2}\right)} * 1.000$

$I_{x}^{t+n}$ : inmigrantes a la edad $x$ en el periodo $t+n$.

$E_{x}^{t+n}$ : emigrantes a la edad $x$ en el periodo $t+n$.

$P_{x}^{t}$ : población al inicio del periodo.

$P_{x}^{t+n}$ : población al final del periodo.

Para estudiar las características de los nuevos emigrantes y compararlos con sus predecesores, se ha recurrido a los microdatos de los Censos de Población de 1981, 1991, 2001 y 2011. Se ha seleccionado a las personas nacidas en Castilla y León que residían en otras CC. AA. y se han tenido en cuenta dos variables censales, una referente al nivel educativo y otra al perfil ocupacional, filtrando a la población entre 25 y 39 años y comparando este rango de edad en el tiempo.

-Nivel de instrucción: primaria o inferior, ESO-EGB-FP1, bachillerato-FP2 y universitarios.

-Perfil profesional, agrupando las distintas categorías CNO en las diez grandes categorías que establece el INE en la clasificación de 2011 (a un dígito). En este caso se han resumido en ocho, unificando en un solo grupo a los trabajadores cualificados de la industria, la construcción y el sector primarios (la última era poco numerosa) y se han eliminado las ocupaciones militares por su heterogeneidad y tener un número de casos reducido. Así pues, las categorías resultantes 
son: servicios personales; ocupaciones elementales; trabajadores de la industria, la construcción y el sector primario; montadores de maquinaria; empleados contables y administrativos; técnicos y profesionales de apoyo; técnicos y profesionales científicos e intelectuales; directivos y gerentes.

Para analizar la distribución espacial de la población emigrada se han utilizado los microdatos del Padrón Municipal de Habitantes de 2016. Aunque esta fuente no proporciona información socioeconómica tan completa como la del censo, permite tener una visión temporal más reciente y localizar a los emigrados según su sección censal de residencia. Se ha seleccionado el stock de personas nacidas en Castilla y León en tres grupos etarios, 25-39, 40-64 y más de 65. Primeramente, se ha ubicado a los emigrados a escala nacional en los respectivos municipios de destino, en números absolutos. A continuación, se han estudiado las pautas de localización urbana de los emigrantes en los municipios de Madrid y Barcelona, mediante la aplicación de cocientes de localización y la posterior elaboración de un mapa de calor ${ }^{63}$.

Cociente de localización: $Q_{l x}=\frac{\frac{P_{x s}}{P_{t s}}}{\frac{P_{x}}{P_{t}}}$

$P_{x s}:$ población $\mathrm{x}$ en la sección $\mathrm{s}$.

$P_{t s}:$ poblacion total de la sección s.

$P_{X}$ : población x en el conjunto del territorio.

$P_{t}$ : población total del territorio.

\section{El aumento de la intensidad emigratoria: la población autóctona como protagonista de los flujos de salida}

La dinámica migratoria del conjunto de provincias que componen Castilla y León, a grandes rasgos, se ha comentado en el apartado teórico. En este epígrafe se pretende hacer un breve repaso de los movimientos migratorios desde 1962 hasta 2015 y prestar especial atención al periodo 1988-2015, cuando es posible diferenciar la naturaleza de las salidas y entradas regionales, haciendo hincapié en la población autóctona, objeto de estudio por parte del presente artículo.

En la Figura 1 se puede apreciar la tendencia emigratoria, inmigratoria y el saldo del periodo 1962-2015 $5^{64}$. Se observa un elevado contingente emigratorio entre los años 60 y mediados de los 70, el "vaciamiento demográfico" de Castilla y León ${ }^{65}$ de la etapa desarrollista. Entre 1962 y 1975 el saldo migratorio interior fue de -300.343 personas,

63 Un mapa de calor (“heat map") es un ráster generado a través de la función Densidad de Kernel, que permite obtener las zonas o puntos donde se da la mayor concentración de un fenómeno determinado. En este caso, la concentración residencial de los castellanos y leoneses dentro de los municipios de Madrid y Barcelona.

64 Antes de 1981 no hay datos de inmigración exterior, por lo que se excluyen también las bajas exteriores entre 1962 y 1981; estas últimas suponen en torno a un $20 \%$.

65 Caballero, Delgado y Martínez, 2012. 
unas 21.450 pérdidas anuales, a lo que habría que añadir la emigración exterior, que supuso en torno al 20\% de las salidas. El grueso de la emigración exterior era de carácter temporal y de dirigía hacia los países de Europa Noroccidental, principalmente hacia Alemania, Suiza y Francia. Rapado ${ }^{66}$ estima, a nivel nacional, una proporción de retornos exteriores del $70 \%$ sobre todas las salidas, aunque menciona que estos datos han de ser tomados con cautela. La emigración transoceánica se cuantifica en un $13 \%$ de todas las salidas hacia el extranjero. En este caso, al contrario que en la emigración continental, si se trataba de una salida predominantemente definitiva ${ }^{67}$.

Desde 1975 hasta finales de los 90, la intensidad migratoria es reducida, aunque varía en función de los periodos de expansión y recesión económica ${ }^{68}$. Pese a ello, la emigración sigue siendo más cuantiosa que la inmigración en todos los años. Se incrementa levemente la intensidad migratoria desde la última mitad de los años 80 , sobre todo la inmigración por las corrientes de retorno ${ }^{69}$. Desde la crisis económica de mediados de los 70 hasta finales de los años 90 se pierden alrededor de 3.350 personas anualmente por saldo interior negativo y el balance exterior es ligeramente positivo.

Durante los primeros años del siglo XXI, el saldo migratorio se torna a signo positivo, gracias al porte de la inmigración extranjera, que llega a Castilla y León con cierto retraso respecto al conjunto nacional ${ }^{70}$. No obstante, la emigración interior -también la inmigración- crece considerablemente y alcanza cifras absolutas cercanas a las registradas en los 60 y supera el contingente emigratorio de la primera mitad de los 70. Entre los años 2000 y 2008 Castilla y León tiene un saldo exterior positivo de 156.622 personas, 17.400 al año (2.200 emigrantes y 19.600 inmigrantes), pero pierde 29.239 por saldo interior, 3.250 anualmente (32.550 emigrantes y 29.300 inmigrantes) -extranjeros con una mayor movilidad, pero también población endógena-.

El saldo positivo con el exterior se mantiene hasta 2011 por la reagrupación familiar de los extranjeros, pero desde 2009 el flujo de trabajadores foráneos había comenzado a reducirse. A partir de 2012, el saldo migratorio exterior cae en picado, a lo que se añade un aumento de las pérdidas por balance interior que superan las 7.900 personas al año, con un saldo interno de -31.600 efectivos entre 2012 y 2015 y un balance exterior de -4.590. En suma, el saldo total desde el año 2012 se torna nuevamente a signo negativo. No obstante, ya desde 2002 estaban saliendo de Castilla y León unas 35.000 personas al año hacia otras regiones españolas, cifra que aumenta en los últimos tres años, y a partir de 2009 se suman 10.500 bajas anuales hacia el extranjero. Inicialmente, se ha achacado este repunte emigratorio a la movilidad de la población nacida en el extranjero y a la salida de los mismos hacia otras regiones

\footnotetext{
661985.

67 García Zarza, 1983; Caballero, Delgado y Martínez, 2012.

68 Recaño y Cabré, 2003.

69 Recaño, 2004-a y 2006.

70 Delgado y Martínez, 2016-a y 2016-b.
} 
españolas ${ }^{71}$, pero se verá a continuación, en los saldos desglosados por naturaleza, que la mayor parte de las pérdidas demográficas absolutas causadas por la emigración durante el presente siglo se deben a la salida de población nacida en Castilla y León.

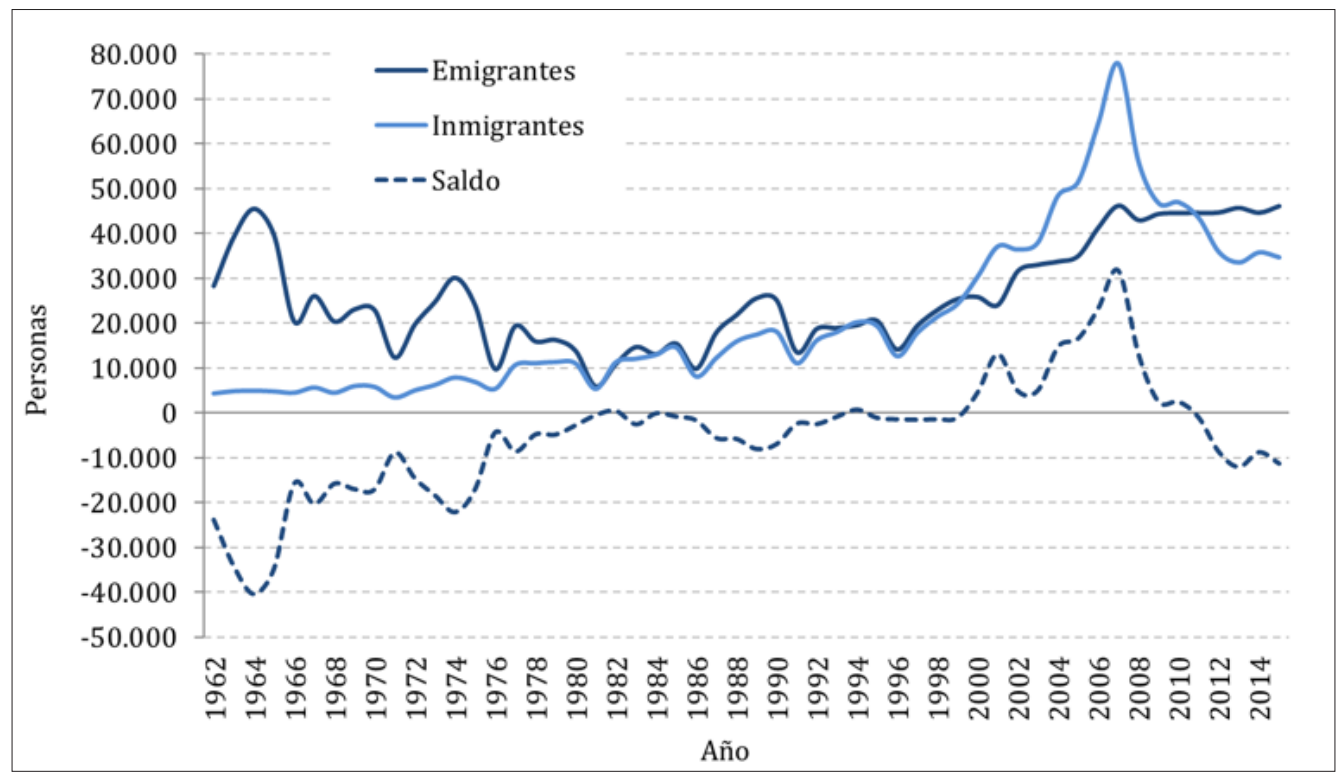

Figura 1: Flujos y saldo migratorio en Castilla y León (interregionales y exteriores), periodo 1962-2015.

Fuente: Elaboración propia, a partir de la EVR de 1988-2015 y de los Anuarios Estadísticos del INE, 1962-2002; los datos de migraciones interiores de 1962 a 1987 han sido facilitados por J. Recaño y proceden de dichos Anuarios.

En la Figura 2 se representan los saldos migratorios por naturaleza entre 1988 y $2015^{72}$ : nacidos en Castilla y León, en otras CC. AA. y en el extranjero. Antes del siglo XXI la población extranjera apenas tenía representatividad, entre los años 2000 y 2009 se puede ver el espectacular incremento del saldo positivo y posteriormente su reducción, por las razones ya comentadas. Respecto a la población nacida en otras regiones españolas, se aprecia una leve ganancia, más numerosa en la primera década del siglo XXI -leve incremento generalizado de la movilidad y adquisición de segundas residencias-. El saldo migratorio de la población autóctona es negativo todos los años, en mayor medida al inicio y al final, no compensado por el exiguo saldo positivo de españoles nativos de otras regiones. Entre 1988 y 2015 se pierden 182.000 castellanos y leoneses por saldo migratorio (437.000 emigrantes y 254.700 inmigrantes que retornaron), 6.500 al año (15.600 bajas y 9.100 altas). Pese a que las pérdidas de autóctonos son ligeramente más acentuadas en los últimos años respecto a los saldos registrados en la década de los 90 y primeros años del siglo XXI, hay que tener en cuenta que los protagonistas de los movimientos migratorios actuales, las personas en las edades de mayor movilidad, son ahora las cohortes vacías, frente a las generaciones abundantes que se movían con anterioridad.

71 Delgado y Martínez, 2016-b.

72 La serie de 1988 a 2001 no incluye emigración exterior -la EVR y los Anuarios Estadísticos del INE no tienen esta información desglosada por naturaleza antes de 2002-, aunque entre finales de los 80 y principios del siglo XXI la emigración hacia el extranjero era prácticamente residual. 
Bien es cierto que hay un aumento generalizado de la movilidad, tanto la emigración como la inmigración se incrementan, pero la primera, que ya era bastante más elevada, crece en mayor medida que la segunda. También se puede apreciar que el grueso de las pérdidas se debe al saldo deficitario de la población autóctona, con un balance negativo más prominente que el de los extranjeros, inclusive en los últimos años del siglo XXI. En adelante, se centra el foco de atención en la población nacida en Castilla y León y se observan los patrones migratorios por edad en distintos periodos. De esta forma, se elimina el efecto de tamaño que tienen las distintas cohortes y se puede apreciar la dimensión relativa del citado aumento de la movilidad entre la población autóctona.

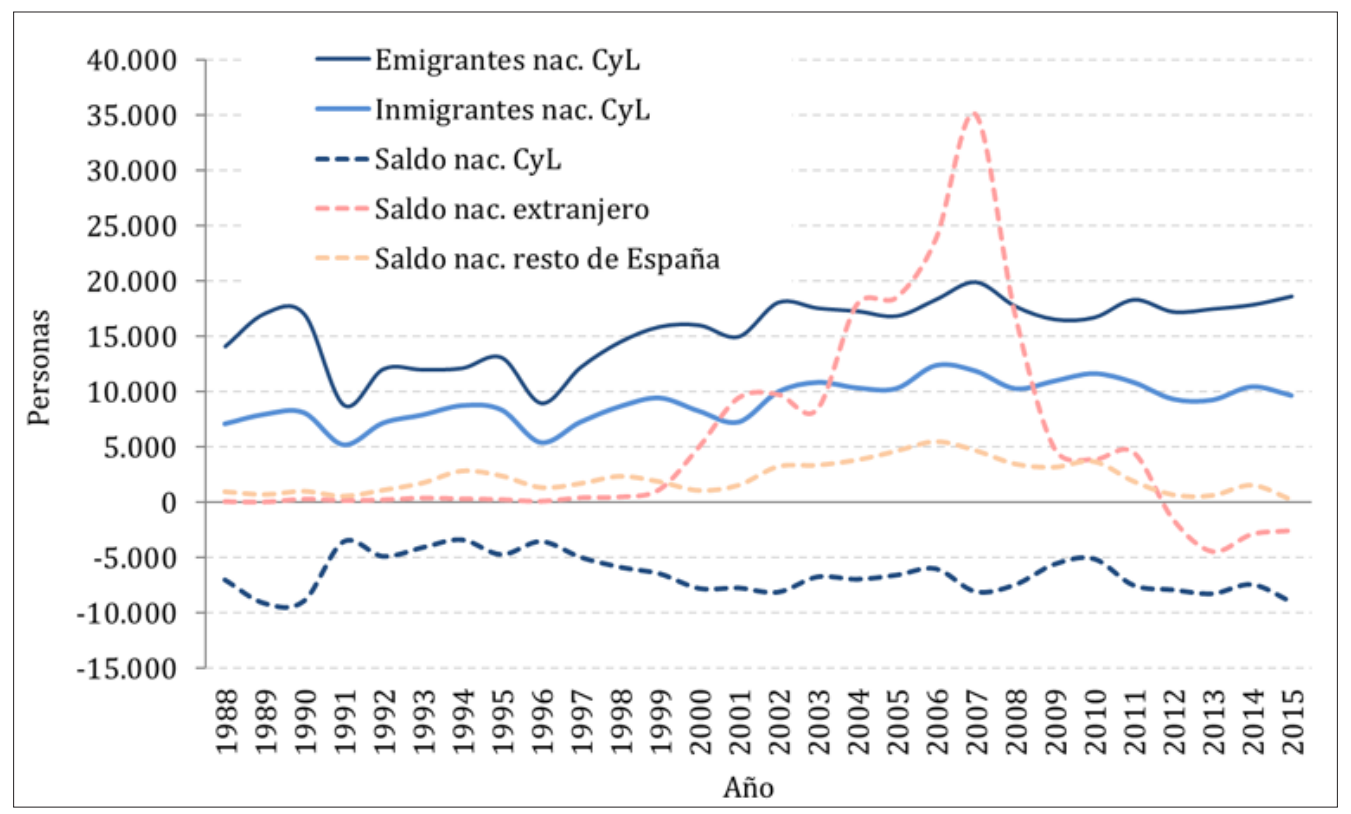

Figura 2: Flujos y saldos migratorios en Castilla y León (interregionales y exteriores), por naturaleza, 1988-2015

Fuente: Elaboración propia, a partir de la Estadística de Variación residenciales, 1988-2015 (INE).

Es necesario aclarar que la mayor parte de los movimientos migratorios de los castellanos y leones son interiores. Los flujos exteriores antes del sigo XXI son prácticamente residuales, pero con posterioridad se produce un ligero incremento. Entre 2002 y 2015 suponen el 6,5 \% de las salidas y el 7,3 \% de las entradas. En los últimos tres años estos porcentajes aumentan considerablemente y alcanzan un 12,4 y 9,9\%, respectivamente. La movilidad exterior de la población local, al igual que las migraciones interregionales, también ha crecido, pero continúa siendo minoritaria y una parte de estos flujos están compuestos por hijos de extranjeros que han nacido en Castilla y León y se mueven arrastrados por la movilidad de sus progenitores. El 20 \% de las bajas exteriores de 2013 a 2015 y el 15,9 \% de las altas de población nacida en Castilla y León pertenecían a individuos menores de 20 años.

En las Figuras 3, 4 y 5 se han calculado las tasas de emigración, inmigración y migración neta, respectivamente, de las personas nacidas en Castilla y León, por grupos de edad quinquenales y para tres periodos: 1991-2000, 2001-2008 y 


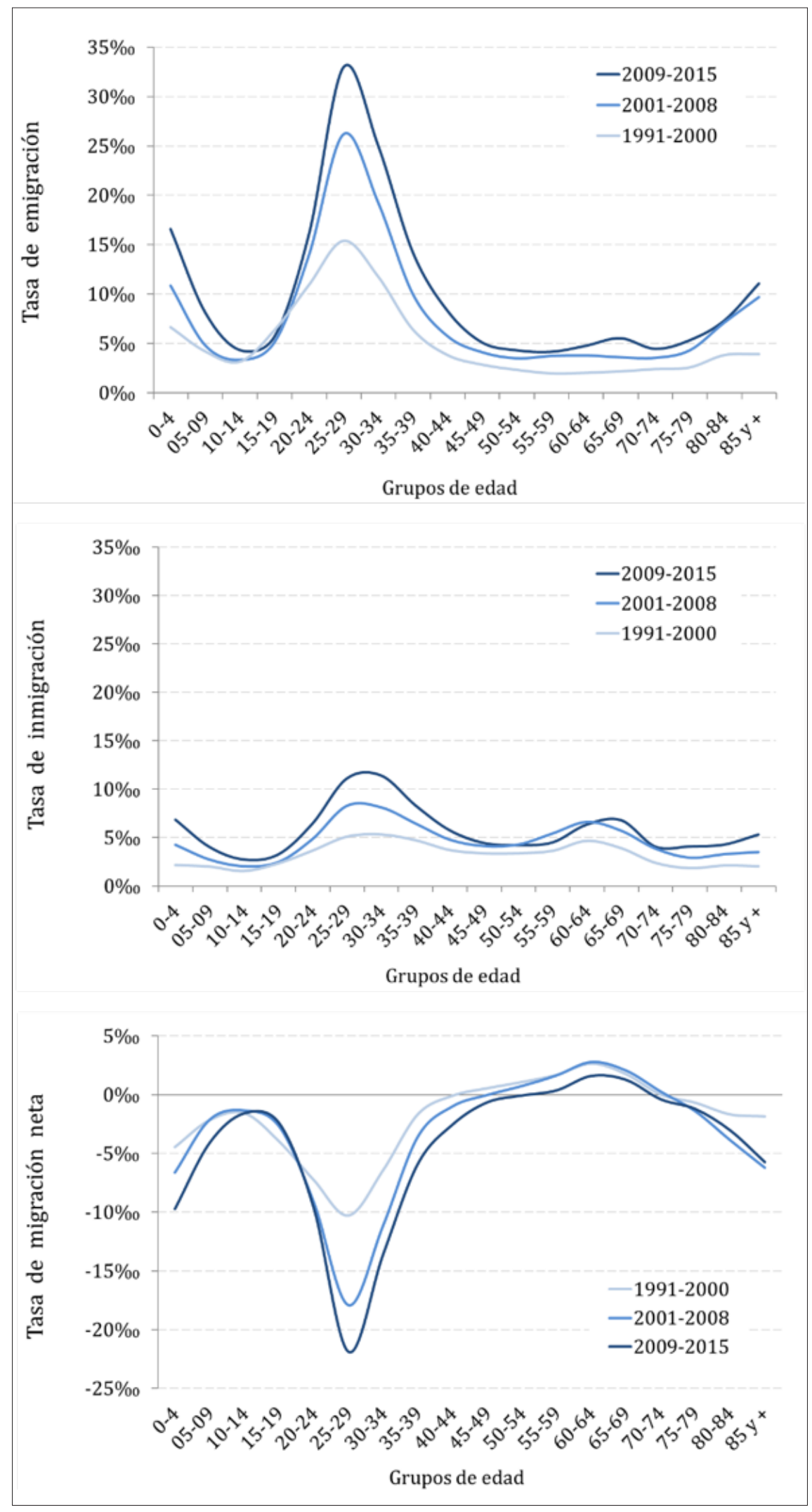

Figuras: 3, 4 y 5: Tasas de emigración, inmigración y migración neta de las personas nacidas en Castilla y León (interregionales y exteriores), por grupos de edad, periodos: 1991-2000, 2001-2008 y 2009-2016

Fuente: Elaboración propia, a partir de la Estadística de Variación residenciales, 1991-2015, los Censo de Población de 1991 y 2001 y el Padrón Municipal de Habitantes de 2009 y 2016 (INE). 
2009-201573. Se puede apreciar que la emigración es bastante más elevada que la inmigración (retornos) entre los activos jóvenes, sobre todo en los grupos de mayor movilidad (25-29, 30-34 y 35-39) y en la migración de arrastre asociada a la doble exponencial del gráfico. También es más cuantiosa a partir de los 75 años, cuando las personas dependientes marchan al lugar de residencia de los hijos emigrados. Entre los 50 y los 70 años la intensidad inmigratoria es más alta que la emigratoria por el retorno y la adquisición de segundas residencias de la población vinculada de este rango etario. Como resultado, tenemos tasas de migración netas negativas en todas las edades, salvo en el caso de la población de mediana edad y los jubilados más jóvenes.

Respecto a la evolución de los patrones de movilidad en el tiempo, se puede afirmar que tanto la emigración como la inmigración se incrementan, pero la primera de manera mucho más marcada. En el grupo 25-29, las tasas de emigración aumentan de un 15,4 \%o en el periodo 1991-2000 a un 26,2 \%o entre 2001 y 2008, hasta alcanzar el 33 \% entre 2009 y 2015. La tasa de emigración también ha aumentado en los demás grupos de edad comprendidos dentro de la doble exponencial y en la emigración de arrastre. Se observa un ascenso, aunque menor, en casi todos los grupos de edad, destacando la población mayor por las razones ya comentadas.

Las tasas de inmigración también han crecido en todos los grupos etarios, aunque bastante menos que la emigración en las edades más móviles. Se observa el pico de las entradas en los grupos 25-29 y 30-34, ligeramente más tardío respecto a la emigración: retorno de algunos jóvenes que marcharon fuera para incorporarse al mercado de trabajo, realizar estudios de grado y posgrado o funcionarios que regresan cuando pueden elegir nuevos destinos. La tasa de inmigración del grupo 25-39 en el periodo 1991-2000 se situaba en el 5,1 \%o, asciende al 8,3\%o entre 2001 y 2008 y en el sexenio 2009-2015 alcanza un 11,1\%o.

En consiguiente, se puede afirmar que hay un aumento de la movilidad bastante más marcado del que revelan los flujos migratorios y las tasas totales, sobre todo en el caso de la emigración. Las tasas de emigración en el grupo más móvil, 25-29, pasaron de un 15,4 a un 33 \%, mientras que las de inmigración lo hicieron de un 5,1 a un 11,1 \% . Como resultado, la tasa de migración neta de este rango etario pasó de un -10,3 \%o en el primer periodo estudiado a un -17,9 \%o en el segundo, hasta alcanzar el -21,9 \%o entre 2009 y 2015. En consiguiente, las tasas de migración netas de los grupos más móviles, aparte de ser negativas en los tres periodos, siguen una dinámica recesiva. En el caso de los individuos más longevos sucede exactamente lo mismo. Únicamente se registran tasas con valores positivos entre los retornados en edad de jubilación y algunas personas en de edad mediana dentro del ciclo de vida residencial, pero la ganancia relativa es menor en el periodo 2009-2015.

73 Entre 1991y 2001 no se incluye emigración exterior, la EVR no dispone de esta información. 




Figuras: 6, 7 y 8: Tasas de emigración, inmigración y migración neta de las personas nacidas en Castilla y León (interregionales y exteriores), por sexo y grupos de edad, periodos: 1991-2000, 2001-2008 y 2009-2016

Fuente: Elaboración propia, a partir de la Estadística de Variación residenciales, 1991-2015, los Censo de Población de 1991 y 2001 y el Padrón Municipal de Habitantes de 2009 y 2016 (INE). 
Si se desglosan los patrones migratorios por sexo, Figuras 6, 7 y 8, se observa una mayor intensidad migratoria y más temprana de las mujeres. Las diferencias no son tan marcadas entre 1991 y el año 2000, pero se incrementan a lo largo del tiempo. En el periodol991-2000 la tasa de emigración femenina del grupo 25-29 era del 16,2 \%о (hombres: $15 \%$ ) y la tasa de inmigración del 4,9\%o (varones: 5,3\%o), valores que aumentaron hasta alcanzar el 37,3 \%o (hombres: $29 \%$ ) y el 12,7 \%o (varones: 9,6 $\%$ ), respectivamente, en el periodo 2009-201574. La mayor movilidad femenina se explica, en parte, por el elevado nivel educativo de las féminas y, por consiguiente, de unas expectativas más altas para obtener mejores empleos en destino. La migración diferencial en favor de las mujeres, según revelan otras investigaciones, desaparece si se controla por los factores individuales del individuo, especialmente por el nivel de instrucción, otorgando a los varones una mayor propensión a emigrar en igualdad de condiciones ${ }^{75}$ (mismo logro educativo, estado civil, paternidad...).

Los hombres presentan una mayor movilidad en edades superiores a los 35 años. Esta diferencia en las tasas de emigración se mantiene hasta llegar a los 60 años, cuando ambos sexos se equilibran; mientras que las tasas de inmigración continúan siendo más elevadas bien entrada la edad de jubilación. En edades avanzadas, la emigración y la inmigración son más intensas en el caso de las mujeres, pero el balance es bastante equilibrado por sexo. En cuanto a las tasas netas de migración, se aprecia el resultado esta dinámica: mayores pérdidas y de forma más temprana entre las mujeres y más acusadas, aunque en menor medida, entre los hombres a partir de los 35 años.

En definitiva, el análisis de las tasas por edad ha permitido constatar un aumento importante de la movilidad allende los límites regionales, especialmente en lo que a las bajas se refiere. Las cohortes vacías, grandes protagonistas de los actuales flujos de salida, emigran con mucha mayor intensidad que sus predecesores, especialmente las mujeres. Este es un resultado que debe subrayarse y que puede pasar desapercibido si se analizan las tasas respecto al conjunto de la población, pues en el denominador siguen estando presentes los baby boomers. Sin embargo, desglosando las tasas por edad, es evidente que se está produciendo una notable reactivación de la emigración entre los activos jóvenes de Castilla y León, generaciones que pertenecen a las cohortes vacías.

\section{El perfil de los migrantes: procedencia urbana, fuga de talento y nuevas preferencias de localización en destino}

En este apartado se realiza una caracterización del perfil de los migrantes internos castellanos y leoneses, estableciendo una comparación con los emigrantes de etapas anteriores y las personas que han abandonado la región de manera reciente. Las variables estudiadas son: ámbito territorial de procedencia, nivel de instrucción, perfil profesional y localización en destino -a nivel municipal para el conjunto de España y dentro de las principales ciudades receptoras, Madrid y Barcelona, por secciones censales-.

74 Entre 1991y 2001 no se incluye emigración exterior, la EVR no dispone de esta información.

75 Recaño, 2014, 2015-a y 2015-b; González-Leonardo y López Gay, 2019. 


\section{El vaciamiento de las ciudades}

A través de las bajas de la Estadística de Variaciones Residenciales entre 1988 y 2015, se observa un peso creciente de los ámbitos urbanos como territorio de procedencia entre los emigrantes autóctonos de 25 y 39 años (Cuadro 1). Entre 1988 y 1999, el 39,3 \% de las bajas se registraron en las capitales de provincia, frente al 50,5 \% del periodo 2009-2015. Las áreas de influencia urbana han pasado de un 2,9 a un 8,9\%. Los municipios no capitales con más de 10.000 habitantes también aumentan su representatividad, aunque en menor medida, desde el 8,6 \% hasta el 9,8 \%. El ámbito territorial que engloba el conglomerado de municipios entre 10.000 y 5.001 habitantes se mantiene más o menos estable, en torno al $6 \%$. Los términos municipales de 5.000 a 2.000 personas manifiestan una tendencia decreciente, pero no es demasiado llamativa (de un 6,3 a un 5,7 \%). Los territorios más netamente rurales, los menores de 2.000 individuos, experimentan un descenso d 18 puntos porcentuales en la proporción de las bajas totales, de un 37,1 a un 19,1 \%. En este aspecto, a mayores de la propia intensidad emigratoria, entra en juego el stock de población residente en estos espacios. Los ámbitos urbanos, sobre todo las áreas de influencia urbana por el proceso de desconcentración de las capitales, han aumentado la proporción de habitantes pertenecientes al rango etario estudiado en el conjunto regional, al contrario de lo que ha sucedido en los municipios rurales, que han experimentado una reducción sustancial del número de jóvenes autóctonos.

Cuadro 1: Proporción de emigrantes autóctonos (interregionales y exteriores) de Castilla y León entre 25 y 39 años, por ámbito territorial de procedencia: 1988-1999, 2000-2008 y 2009-201576

\begin{tabular}{|c|c|c|c|c|c|c|}
\hline Periodo & Capitales & $\begin{array}{c}\text { Áreas de } \\
\text { influencia } \\
\text { urbana }\end{array}$ & $\begin{array}{l}\text { No capitales } \\
>10.000 \text { hab. }\end{array}$ & $\begin{array}{c}10.000-5.001 \\
\text { hab. }\end{array}$ & $\begin{array}{c}5.000-2.000 \\
\text { hab. }\end{array}$ & $<2.000$ hab. \\
\hline $1988-1999$ & $39,3 \%$ & $2,9 \%$ & $8,6 \%$ & $5,7 \%$ & $6,3 \%$ & $37,1 \%$ \\
\hline $2000-2008$ & $49,4 \%$ & $5,8 \%$ & $9,6 \%$ & $5,8 \%$ & $5,4 \%$ & $24,1 \%$ \\
\hline $2009-2015$ & $50,5 \%$ & $8,9 \%$ & $9,8 \%$ & $6,0 \%$ & $5,7 \%$ & $19,1 \%$ \\
\hline
\end{tabular}

Fuente: Elaboración propia, a partir de la EVR entre 1988 a 2015 (INE).

En el Cuadro 2 se calcula el porcentaje de emigrantes y de población autóctona residente del rango etario estudiado en cada uno de los ámbitos territoriales, así como, las tasas de emigración para los periodos 2000-2008 y 2009-201577. De esta forma, se puede saber si hay una mayor intensidad emigratoria en los ámbitos urbanos o si los resultados obtenidos en el Cuadro 1 derivan simplemente de la distribución de los stocks poblacional en los municipios. En ambos periodos las capitales presentan las tasas emigratorias más elevadas de toda la región, con una dinámica creciente: 20,2 \%o en 2000-2008 y 27,1 \%o. en 2009-2015. En general, todos los ámbitos territoriales aumentan

76 Las áreas de influencia urbana corresponden a la delimitación del Atlas Estadístico de las Áreas Urbanas del Ministerio de Fomento; para establecer el tamaño del municipio se ha tomado como referencia el Padrón Municipal de Habitantes de 2016.

77 Las áreas de influencia urbana corresponden a la delimitación del Atlas Estadístico de las Áreas Urbanas del Ministerio de Fomento; para establecer el tamaño del municipio se ha tomado como referencia el Padrón Municipal de Habitantes de 2016. 
sus tasas emigratorias. Las ciudades no capitales menores de 10.000 habitantes y los ámbitos rurales de 10.000 a 2.000 individuos, los centros comarcales de servicios, incrementan de forma notable la intensidad expulsora hacia otras CC. AA., pero aún están lejos de los valores de las principales ciudades de Castilla y León. Los municipios menores de 2.000 habitantes, aunque crecen sus tasas de emigración, se consolidan como el ámbito territorial menos emigratorio allende los límites regionales.

Cabe destacar, que las personas del medio rural son más propensas a los movimientos de corta distancia, hacia las áreas urbanas de las ciudades de la propia provincia o región o, en el caso del rural profundo, hacia los respectivos centros comarcales de servicios. Los individuos de las capitales, sin embargo, tienen una mayor presencia en los movimientos migratorios de larga distancia. También habría que considerar que las capitales son utilizadas como puente por los autóctonos de ámbitos territoriales menores, que finalizan en ellas su formación o acceden al mercado de trabajo durante la etapa de incorporación laboral, siguiendo un proceso de migración encadenada antes de abandonar la región.

Cuadro 2: Proporción de emigrantes (interregionales y exteriores) y de población autóctona entre 25 y 39 años, por ámbito territorial de procedencia, y tasas de emigración, 2000-2008 y 2009-2015

\begin{tabular}{|l|r|r|r|r|r|r|}
\hline \multicolumn{1}{|c}{} & \multicolumn{2}{|c}{ Ámbito territorial } & \multicolumn{2}{c}{ Periodo 2000-2008 } & \multicolumn{2}{c|}{ Periodo 2009-2015 } \\
& Emigrantes & $\begin{array}{c}\text { Población } \\
\text { media }\end{array}$ & $\begin{array}{c}\text { Tasa de } \\
\text { emigración }\end{array}$ & Emigrantes & $\begin{array}{c}\text { Población } \\
\text { media }\end{array}$ & $\begin{array}{c}\text { Tasa de } \\
\text { emigración }\end{array}$ \\
\hline Capitales de provincia & $49,4 \%$ & $43,7 \%$ & $20,2 \%$ & $50,5 \%$ & $43,1 \%$ & $27,1 \% 0$ \\
\hline Áreas de influencia urbana & $5,8 \%$ & $9,4 \%$ & $11,0 \%$ & $8,9 \%$ & $12,0 \%$ & $16,7 \% 0$ \\
\hline No capitales >10.000 hab. & $9,6 \%$ & $9,3 \%$ & $18,4 \%$ & $9,8 \%$ & $10,2 \%$ & $22,1 \% 0$ \\
\hline $5.001-10.000$ hab. & $5,8 \%$ & $6,2 \%$ & $16,6 \%$ & $6,0 \%$ & $6,2 \%$ & $22,4 \% 0$ \\
\hline $2.001-5.000$ hab. & $5,4 \%$ & $6,1 \%$ & $15,9 \%$ & $5,7 \%$ & $6,1 \%$ & $21,5 \% 0$ \\
\hline$<2.000$ hab. & $24,1 \%$ & $25,3 \%$ & $17,0 \%$ & $19,1 \%$ & $22,4 \%$ & $19,9 \%$ \\
\hline
\end{tabular}

Fuente: Elaboración propia, a partir de la EVR de 2009 a 2015 y del PMH de 2000, 2009 y 2016.

\section{Ascenso social y fuga de talento}

Según los datos censales, Castilla y León tiene un nivel educativo bastante alto en comparación al conjunto nacional y se encuentra a la cabeza de la exportación de titulados universitarios hacia el resto de España. El actual éxodo de cerebros contrasta con la emigración de etapas anteriores, donde la mano de obra tenía un nivel de instrucción reducido y emigraba en busca de trabajos poco cualificados en la industria y los servicios personales. Esta tendencia ha sido el resultado de la expansión educativa en España, que comenzó a ser incipiente en las generaciones que nacieron a finales de los años 50 y ha permitido el ascenso social de muchos castellanos y leoneses de origen humilde, materializado a través del estudio y, en muchos casos, del consiguiente acceso al funcionariado.

En la Figura 9 se representa el nivel educativo de los castellanos y leoneses entre 25 y 39 años que residían fuera de la región, comparando los Censos de 1981, 1991, 2001 y 


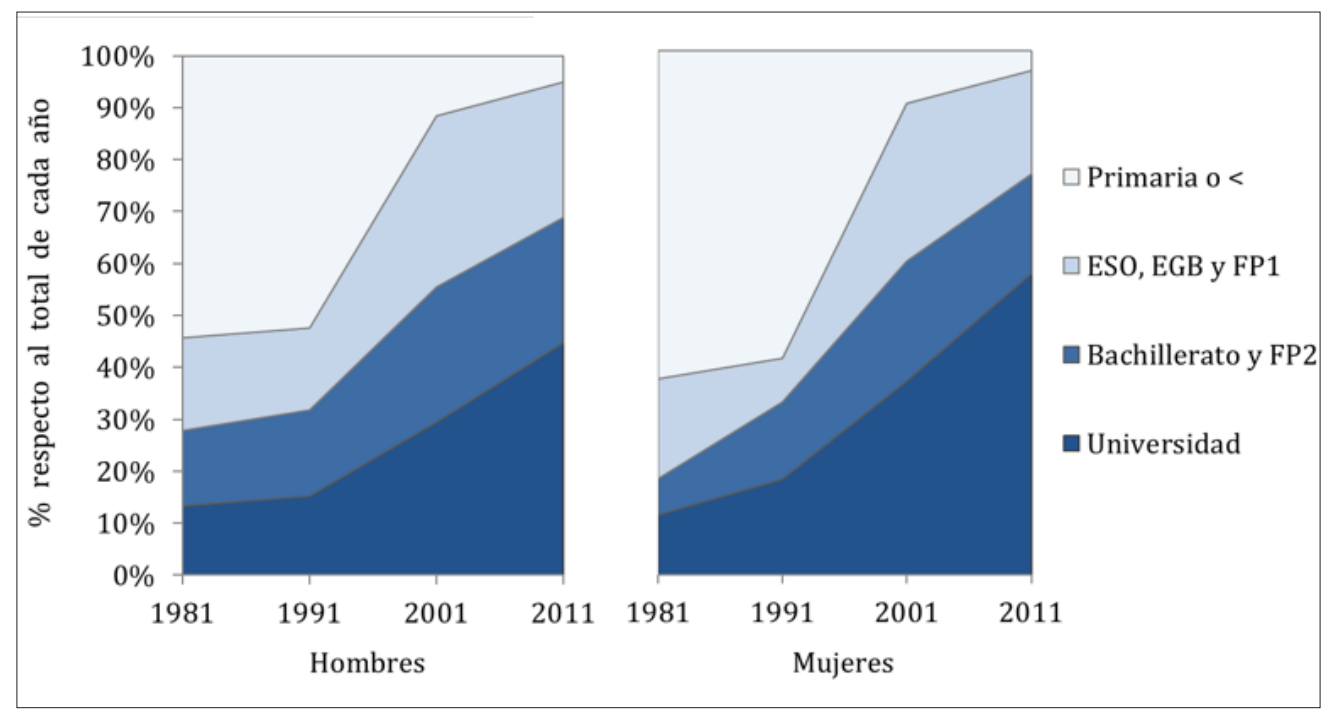

Figura 9: Nivel educativo de los castellanos y leoneses entre 25 y 39 años que residían en otras CC. AA. españolas: 1981, 1991, 2001 y 2011

Fuente: Elaboración propia, a partir de los Censos de Población de 1981, 1991, 2001 y 2011 (INE).

2011. Es bastante evidente el aumento en el nivel de instrucción de este colectivo. En el año 1981, el 58,6 \% de los emigrados no tenía estudios de EGB-ESO-FPI, y en 2011 tan solo un 4,4\%. En el 81, el 12,4 \% estaba en posesión de un título universitario, frente al 51,4 \% del año 2011. Las categorías ESO-EGB-FPl y bachillerato-FP2 han ganado peso a costa de la disminución de la categoría primaria o inferior, aunque han perdido representatividad en los dos últimos censos en favor de los estudios superiores. En el caso de las mujeres, el incremento de los estudios universitarios ha sido abismal. Partiendo de proporciones inferiores a los hombres en 1981, han alcanzado cifras cercanas al 58 \% (varones: $45 \%$ ). Los hombres han canalizado mayores ganancias en el nivel de instrucción hacia la formación profesional media y superior.

En la Figura 10 se representa el nivel de instrucción de la población autóctona se-

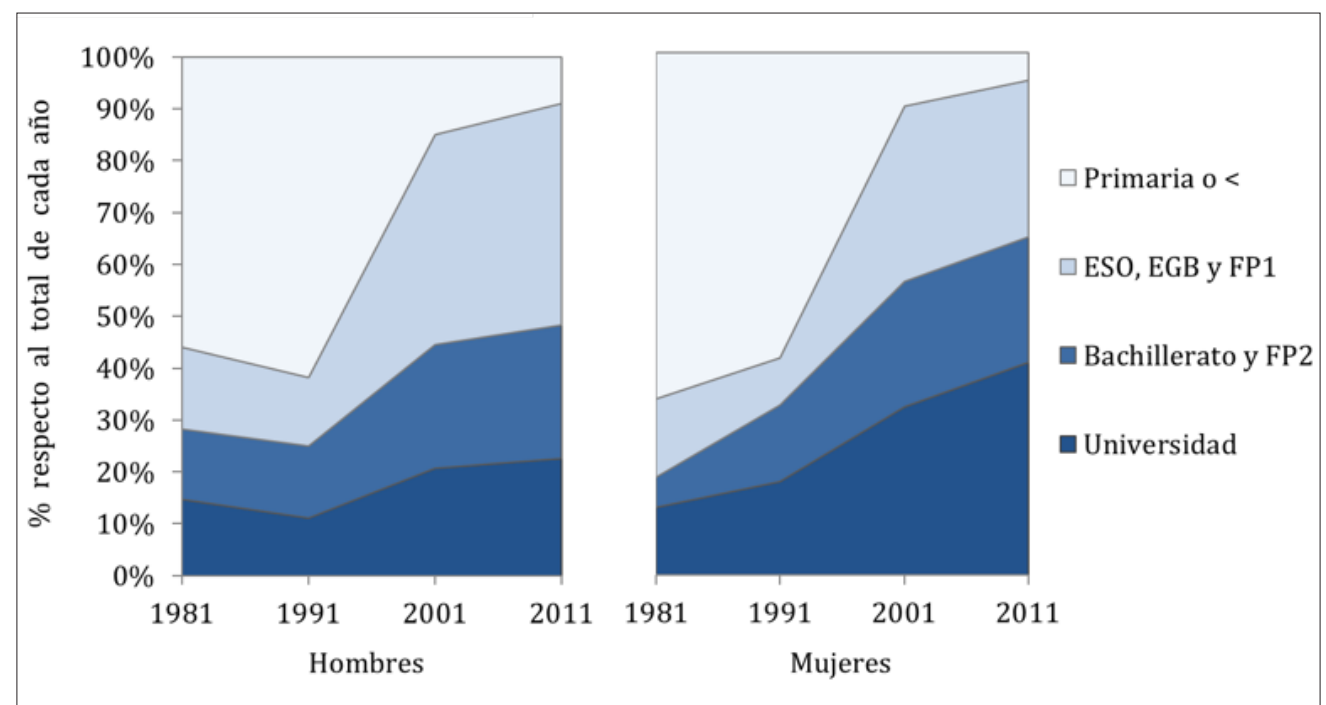

Figura 10: Nivel educativo de los castellanos y leoneses entre 25 y 39 años que residían Castilla y León: 1981, 1991, 2001 y 2011

Fuente: Elaboración propia, a partir de los Censos de Población de 1981, 1991, 2001 y 2011 (INE). 
dentaria. Es destacable que existe un perfil educativo superior en el caso del colectivo emigrado a lo largo de todo el periodo, en línea a literatura referente a la selectividad educativa positiva en las migraciones ${ }^{78}$. En los censos de 1981, 1991 y 2001, el nivel formativo de los emigrantes y de la población sedentaria, aunque superior en el caso de los primeros, es más o menos similar. Sin embargo, las diferencias se incrementan notablemente en el último censo, cuando los emigrantes registran una proporción de titulados universitarios del 51,4\%, frente al 31,2 \% de los sedentarios. El porcentaje de mujeres universitarias que residían en otras CC. AA. era 17 puntos superior respecto a las féminas sedentarias, y un 22 entre los varones. La divergencia entre ambos niveles educativos en el último periodo intercensal, pone de relieve la existencia un marcado desajuste entre el incremento del nivel formativo y la evolución del tejido productivo regional, que se traduce en la emigración de los titulados universitarios.

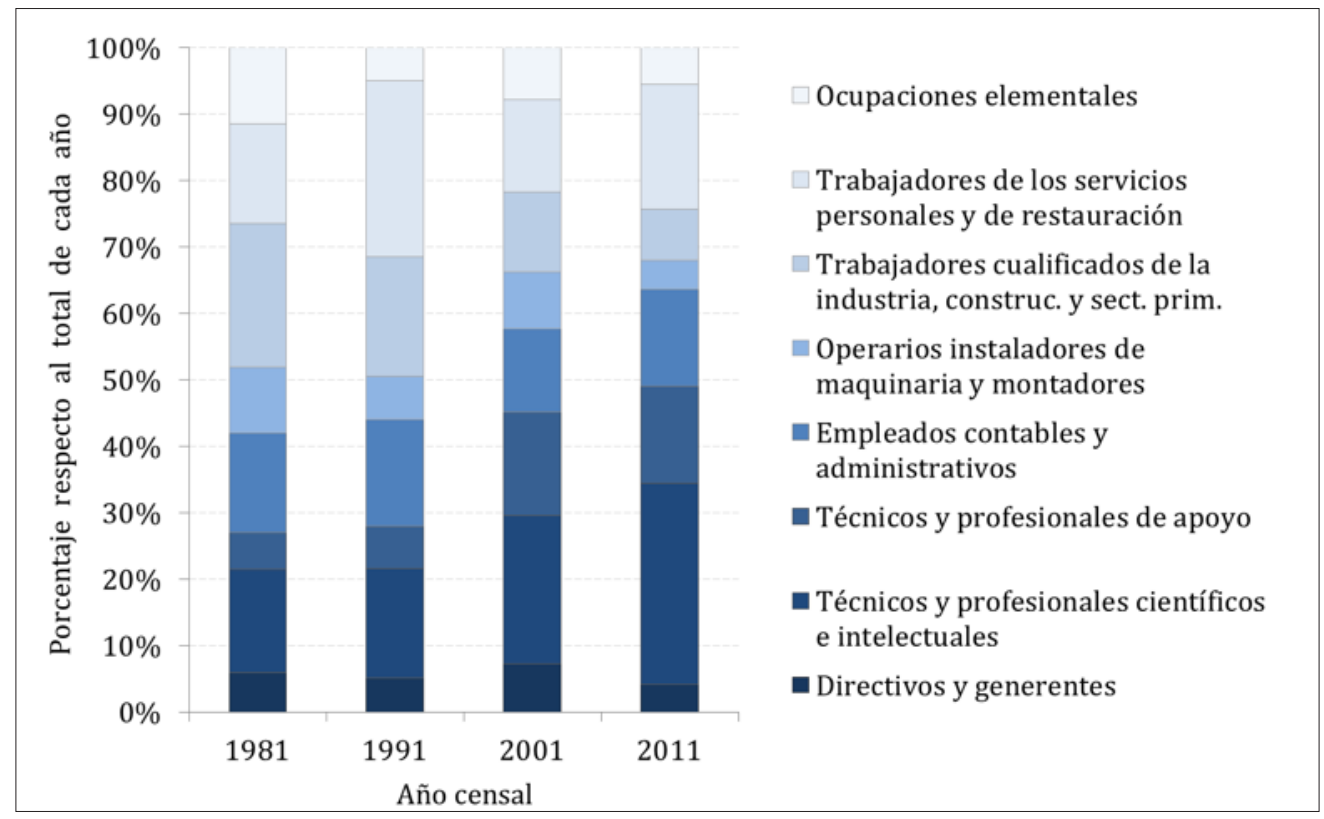

Figura 11: Perfil profesional de los castellanos y leoneses entre 25 y 39 años que residían en otras CC. AA. españolas: 1981, 1991, 2001 y 2011

Fuente: Elaboración propia, a partir de los Censos de Población de 1981, 1991, 2001 y 2011 (INE).

En cuanto al perfil profesional de los emigrados, Figura, 11, se puede distinguir un incremento de la proporción de castellanos y leoneses que trabajaban como técnicos y profesionales científicos e intelectuales; 30,3 \% en 2011 frente al 15,6\% de 1981. La categoría directivos y gerentes crece hasta 2001 (7,3\%), pero posteriormente desciende a un 4,1 \%, por debajo de la cifra de 1981 (5,9\%), como resultado el contexto de crisis económica y el consiguiente cierre de empresas. Técnicos y profesionales de apoyo pasa de un 5,4 a un 14,7 \%. Los empleados contables y administrativos representan un porcentaje similar en 1981 y 2011, pero oscilan entre los periodos intercensales. Servicios personales aumenta de un 14,9 \% en 1981 a un 18,8 en 2011: se aprecia un crecimiento muy llamativo entre 1981 y 1991, vinculado al proceso de terciarización económica; desciende en 2001 y se incrementa con posterioridad. Parece ser que esta 78 Sjaastad, 1962; Gould, 1982; Recaño, 2014 y 2015-b; Bernard y Bell, 2018. 
categoría es inestable en el tiempo y tiene una estrecha relación con diversos factores, entre ellos la coyuntura económica. Las ocupaciones elementales representaban un 5,5\% en el último Censo, seis puntos porcentuales menos que en 1981. Los trabajos industriales, de construcción y del sector primario y los montadores de maquinaria representaban en 2011 proporciones más bajas, 7,7 \% (1981: 21,7) y 4,3 \% (1981: 9,9\%) -reconversión industrial y, más recientemente, crisis del sector de la construcción y de otras actividades relacionadas-.

El perfil profesional de los emigrados ha cambiado notablemente. La categoría de técnicos y profesiones científicos e intelectuales representaba casi un tercio de los empleos en 2011. Junto con directivos y gerentes y a técnicos y profesionales de apoyo alcanzaba el 49,1\%. La representatividad de los empleos industriales ha decrecido considerablemente, principalmente por la reestructuración económica. El incremento de los servicios personales se debe al proceso de terciarización, pero también al aumento de la precariedad e inestabilidad laboral juvenil y la escasa oferta de empleos cualificados. A pesar de que el perfil profesional de los castellanos y leoneses emigrados ha variado significativamente, si se compara con el nivel de instrucción, se puede deducir que existe cierta sobrecualificación en destino, aunque menor que en origen.

\section{La aglomeración madrileña como foco de atracción hegemónico y la dispersión de los destinos secundarios}

Según los datos del Padrón Municipal de Habitantes de 2016, había 3.055.182 castellanos y leoneses en el territorio nacional, el 65,6 \% residían en Castilla y León y el 34,4\% restante en otras CC. AA. En cuanto a los individuos mayores de 65 años, Figura 12, el 47,9 \% (488.258) estaban empadronados en otras regiones, emigrados en su mayor parte durante las oleadas emigratorias masivas del periodo 1955-1975. La distribución actual de esta población nos muestra que el destino principal era la región madrileña $(38,1 \%)$, las áreas minero-industriales del norte de España (Bilbao, Gijón-Oviedo, San Sebastián), Barcelona (11,5 \%) y algunos sectores costeros turísticos del Litoral Mediterráneo. En definitiva, se dirigían a las ciudades más industrializadas con expectativas de convertirse en obreros industriales y, secundariamente, a las áreas turísticas donde se necesitaba mano de obra barata para el sector servicios ${ }^{79}$.

El 37,8 \% de la población entre 40 a 64 años nacida en Castilla y León residía fuera de la región en 2016 (435.782). Los patrones de localización son similares a los del grupo más de 65, aunque las aglomeraciones urbanas del País Vasco pierden poder de atracción, al igual que el Área Metropolitana de Barcelona. Casi todos los destinos tienen una menor presencia de emigrados y hay mayor dispersión, a excepción de la Comunidad de Madrid, que mantiene un porcentaje similar. Una buena parte de estos individuos forman parte de flujos de arrastre asociados a la movilidad de sus progenitores durante la etapa desarrollista. Debido a la importancia de la movilidad familiar

79 Pérez Díaz, 1971 y 1972; García Zarza, 1983. 


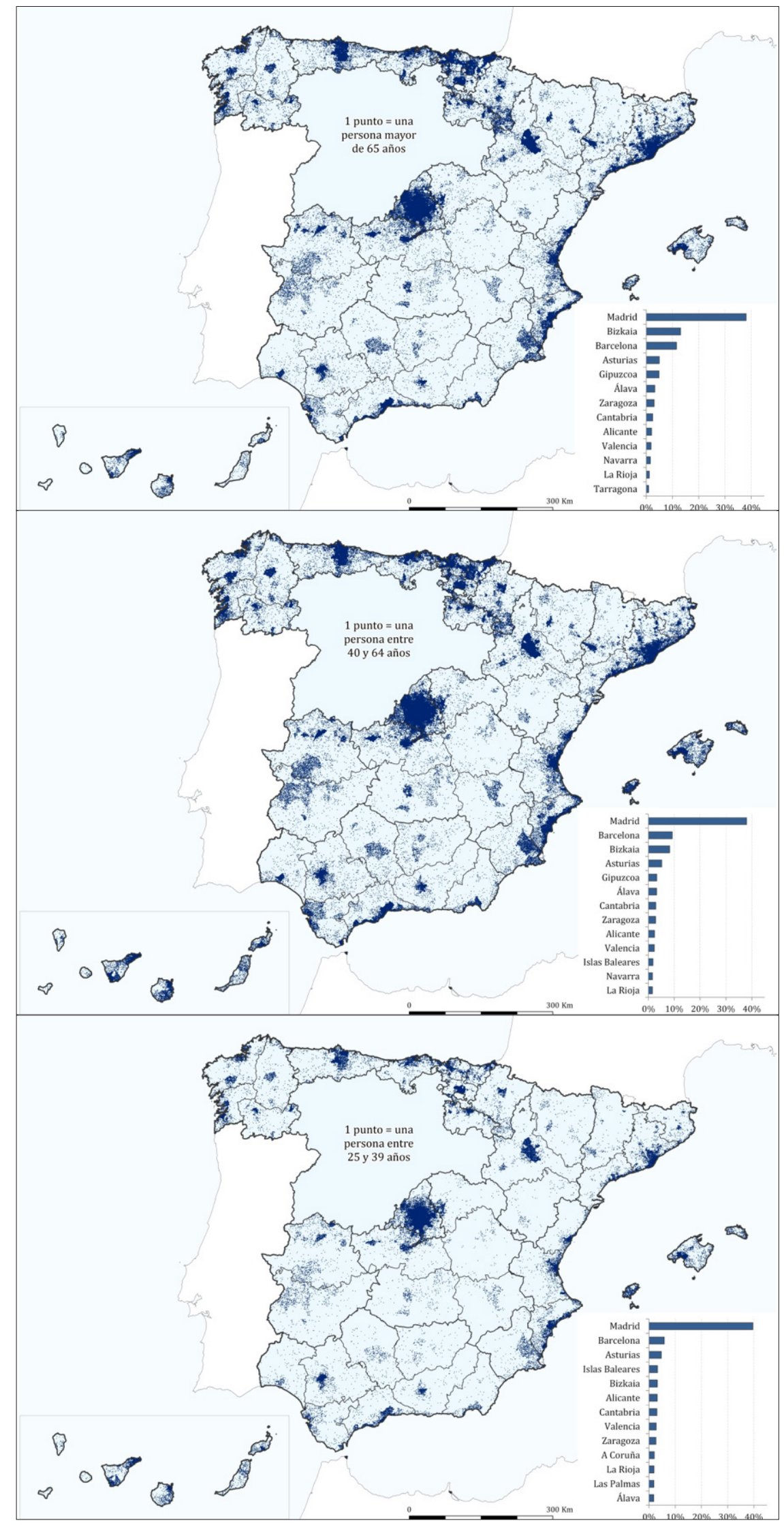

Figuras 12, 13 y 14: Castellanos y leoneses residentes en otras CC.AA. españolas, por municipios, 2016: mayores de 65, 40-64 y de 25 a 39 años Fuente: Elaboración propia, a partir del Padrón Municipal de Habitantes de 2016 (INE). 
durante ese periodo, muchos individuos que nacieron en Castilla y León emigraron a edades tempranas junto a sus padres. De ahí que la proporción de emigrantes sea tan elevada, a pesar de la escasa movilidad laboral entre 1975 y finales de los años 90.

El 22,9 \% de los castellanos y leoneses de 25 a 39 años residían en otras regiones españolas (96.755). Como hemos podido corroborar a través de los datos de la EVR, la intensidad emigratoria es más alta en las generaciones recientes respecto a las personas de cohortes precedentes. La disminución de la proporción de emigrados deviene, en primer lugar, de una reducción de los movimientos migratorios de carácter familiar a lo largo del tiempo; es decir, la emigración de arrastre ha perdido peso, mientras que la movilidad individual cobra cada vez mayor importancia. A mayores, al tratarse de un stock y no de una fuente tipo flujo, la población más joven aún está expuesta al riesgo de emigrar y es de esperar que en los próximos años, según la dinámica creciente observada en las tasas de emigración, efectúen la migración correspondiente, con el consiguiente aumento del stock padronal de emigrados. En cuanto a los destinos elegidos para el grupo 25-39, el $40 \%$ de los emigrados se ubicaban en la Comunidad de Madrid, Figura 14, cuya área metropolitana aumenta el poder de atracción. La provincia de Barcelona sigue perdiendo atractivo respecto a generaciones anteriores $(<6 \%)$, pero el descenso es más acentuado en el caso del País Vasco, cuyas áreas urbanas contaban con menos efectivos que Asturias o Illes Balears. Se puede afirmar que, a excepción de Madrid que se afianza como centro receptor, existe un cambio significativo en los patrones de localización de los actuales emigrantes. Los polos industriales hacia los que se focalizaba la emigración de los 60 y 70 han desaparecido como grandes áreas de atracción ${ }^{80}$, pues la mayor parte del tejido industrial de la época ha quedado desmantelado. Por otra parte, la expansión educativa ha generado una población cada vez más formada, que busca empleos cualificados en lugares que concentran actividades tecnológicas ${ }^{81}$. La cercanía también juega un papel fundamental en las preferencias de los emigrantes ${ }^{82}$ y se aprecia la diversificación en los destinos secundarios descrita en la literatura ${ }^{83}$.

\section{De las barriadas obreras a los sectores centrales de las ciudades globales}

Para profundizar en los patrones de asentamiento de los castellanos y leoneses en el interior de las ciudades, se ha estudiado el caso de las dos principales ciudades receptoras, Madrid y Barcelona, y se ha ubicado a los emigrados según los grupos de edad establecidos anteriormente. En ambos casos se distinguen unas pautas de localización completamente distintas entre los antiguos emigrados y los recientes flujos de salida.

En el municipio de Madrid se observa una presencia notable de población mayor de 65 años en los distritos meridionales, Figura 15 -Latina, Carabanchel, Villaverde,

80 Cabré, Moreno y Pujadas, 1985; García Barbancho y Delgado Cabeza, 1988.

81 Sassen, 1993.

82 Zipf, 1946; Arango, 1985.

83 Olano, 1990); Ródenas, 1994; Recaño, 2004-b y 2006. 


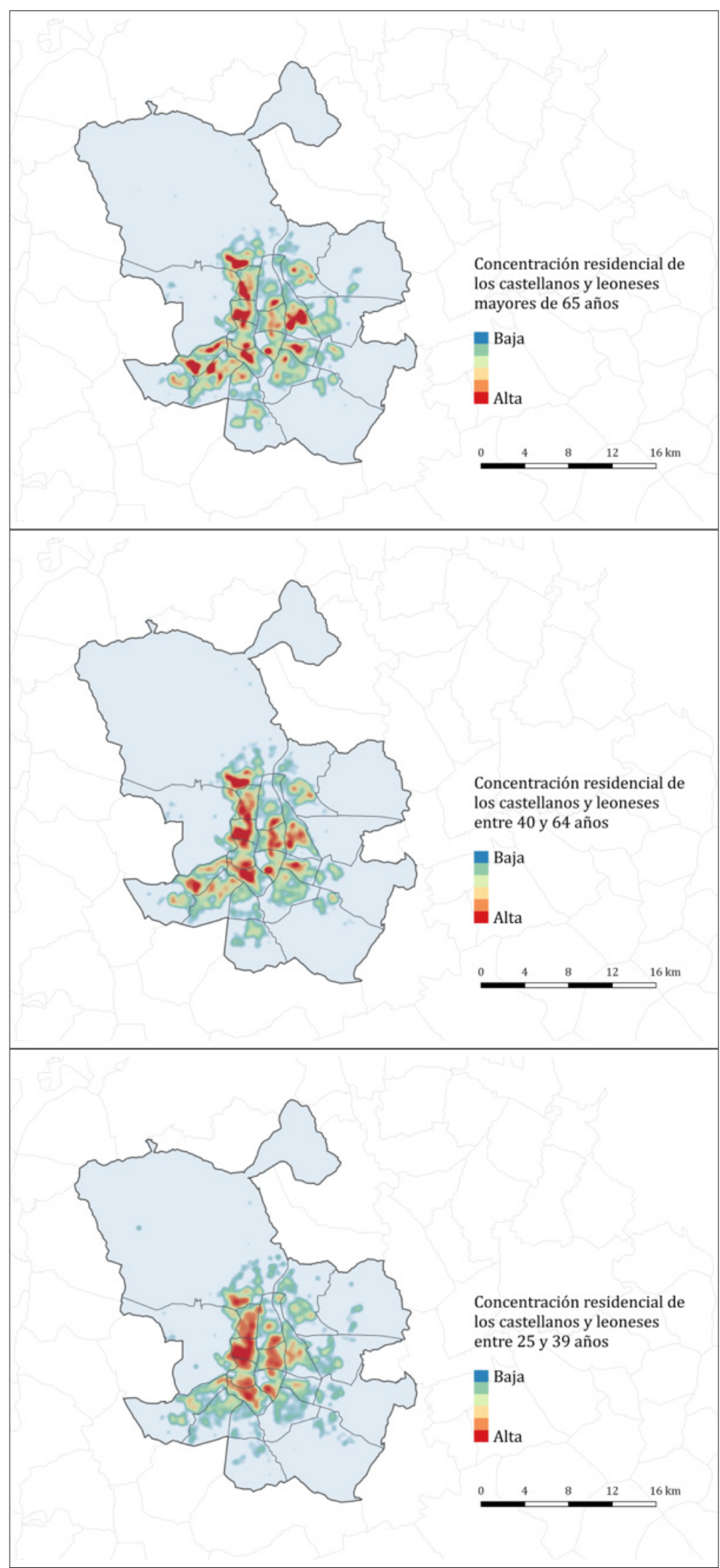

Figuras 15, 16 y 17: Concentración residencial de la población nacida en Castilla y León en el municipio de Madrid, por secciones censales, 2016: personas entre 25 y 39 años, de 40 a 64 y más de 65

Fuente: Elaboración propia, a partir del Padrón Municipal de Habitantes de 2016 (INE). 


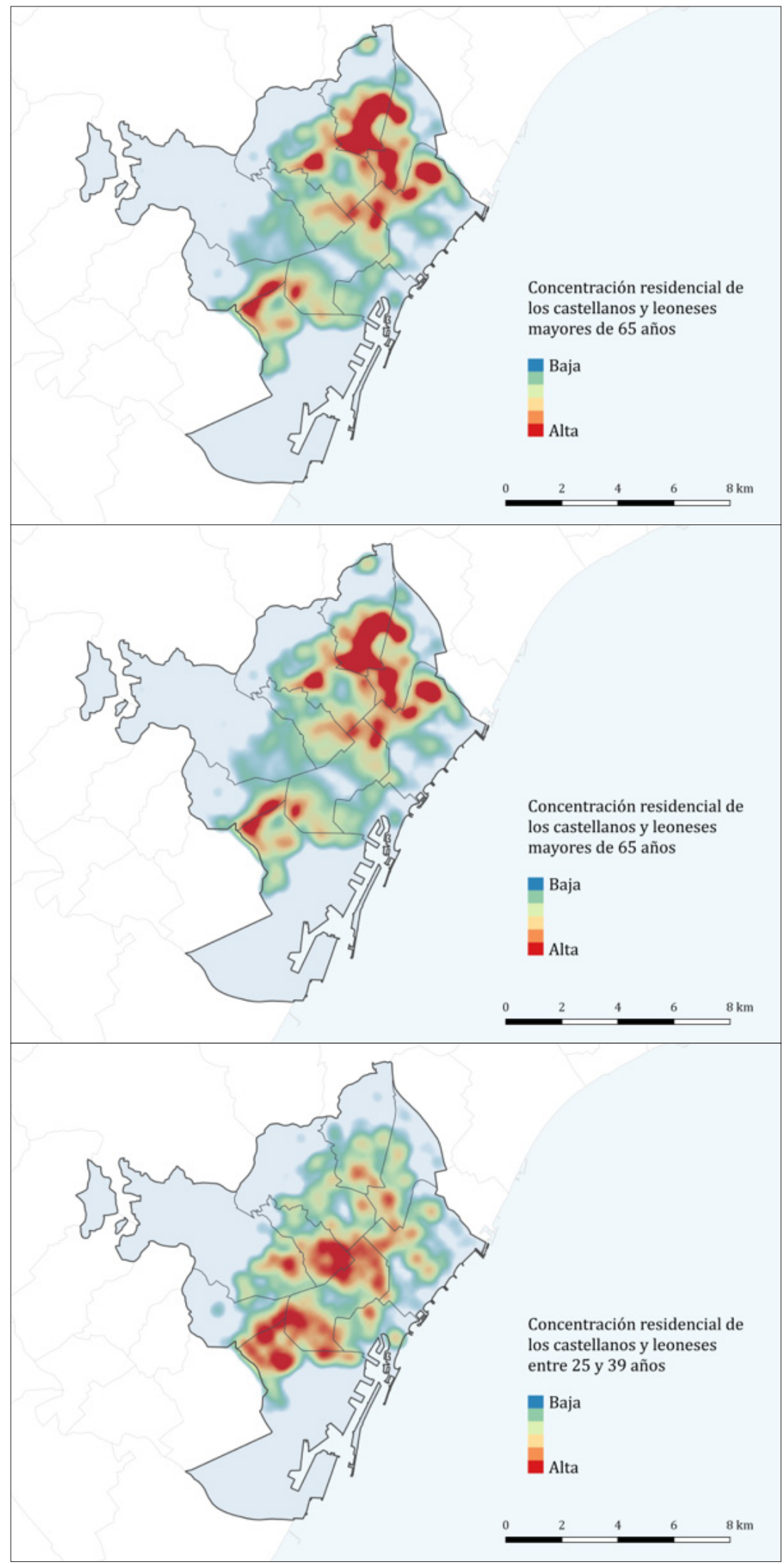

Figuras 18, 19 y 20: Concentración residencial de la población nacida en Castilla y León en el municipio de Barcelona, por secciones censales, 2016: personas entre 25 y 39 años, de 40 a 64 y más de 65

Fuente: Elaboración propia, a partir del Padrón Municipal de Habitantes de 2016 (INE). 
Puente de Vallecas-; aunque se puede apreciar cierta heterogeneidad, con castellanos y leoneses en sectores de clase media -Fuencarral, Chamberí, Ciudad Lineal-. En la Figura 16, en la que se representa a la población de 40 a 64 años, se distingue una menor presencia en los barrios del sur y la extensión de este colectivo hacia el centro de la ciudad, con una mayor concentración en el Barrio de Salamanca y El Retiro. En la Figura 17, castellanos y leoneses entre 25 y 39 años, la presencia en los distritos meridionales es prácticamente residual y hay una marcada concentración residencial en el centro urbano -Centro, Chamberí, Tetuán, Retiro, Barrio Salamanca-. La ubicación de los emigrados corresponde al nivel educativo y social de cada época, que se manifiestan en procesos segregativos del espacio urbano ${ }^{84}$.

En el municipio de Barcelona, la población emigrada mayor de 65 años, Figura 18, se ubica principalmente en las barriadas obreras localizadas en los distritos septentrionales de la ciudad: Nou Barris, Horta-Guinardó, Sant Andreu y Sant Martí. También, aunque en menor medida, en la frontera entre Les Corts y Sants-Montjuïc. En la Figura 19, donde se representa la población de 40 a 64 años, se observa un patrón similar de concentración, pero se distingue una mayor presencia de castellanos y leoneses en el citado sector fronterizo de Les Corts, Sants-Montjuïc, y al sur de Eixample. También se aprecia una localización incipiente al norte de Eixample y Gràcia y una mayor concentración al sur de Sant Martí, a la par que se reduce en Nou Barris y Horta-Guinardó.

La población de 25 a 39 años, Figura 20, ha modificado sus pautas de localización de forma radical en el municipio de Barcelona. La concentración de castellanos y leoneses al norte de la ciudad se ha reducido drásticamente, mientras que las mayores densidades se identifican en el corazón del distrito de Gràcia y en los barrios de Sagrada Família, Dreta de l'Eixample y Fort Pienc, en el distrito del Eixample. Al sur, los barrios de Sants, Hostafrancs, Sant Antoni y Poble Sec también aparecen como zonas de asentamiento preferente. Asimismo, se distingue una incipiente presencia en los barrios del Putxet i el Farró y Sant Gervasi-Galvany, y en el barrio de Sant Pere, Santa Caterina i la Ribera (Ciutat Vella).

Se puede concluir que los patrones de localización urbana de los castellanos y leoneses emigrados han cambiado por completo. Nada tiene que ver la segregación de los flujos de salida más longevos en las barriadas obreras de los distritos de clase trabajadora con las nuevas preferencias residenciales de los actuales emigrantes, que se ubican en sectores bien valorados de los distritos centrales de las ciudades o en aquellos en los que se están experimentando fuertes procesos de gentrificación. La expansión educativa y el ascenso social de los castellanos y leoneses de origen humilde ha sido la constante a lo largo de las últimas décadas y, por consiguiente, también de su población emigrante, que actualmente está compuesta por individuos con un estatus socioeconómico más alto. La ubicación de los actuales emigrados, las cohortes vacías con un nivel de instrucción elevado, parece corresponder con la 
carrera residencial por vivir en los barrios más elitizados de la ciudad de Barcelona ${ }^{85}$.

\section{Conclusiones}

Los hallazgos empíricos observados confirman la hipótesis de partida referente a la movilidad de los castellanos y leoneses. Las migraciones de larga distancia -las interregionales y las exteriores- se han incrementado notablemente entre la población autóctona en los 15 primeros años del siglo XXI, durante los años de bonanza económica y también en el transcurso de la crisis. La emigración de la población adulta joven, a mayores de continuar con la hegemonía que le caracteriza en Castilla y León, creció en mayor medida que la inmigración y la tasa de migración neta negativa se ha duplicado respecto la década de 1990. Para cuantificar la intensidad de los movimientos migratorios es indispensable calcular tasas específicas por edad, en vez de analizar únicamente los flujos y saldos en términos absolutos, pues el tamaño de las distintas generaciones impide apreciar si la movilidad ha variado de manera relativa. Actualmente son las generaciones vacías, nacidas a partir de 1980 pero sobre todo en la primera mitad de la década de los 90, las que se encuentran en las edades de mayor propensión migratoria, frente a las abundantes e inmóviles cohortes del baby boom de los años 60 y la primera mitad de los 70, que se movían en los 80 y 90. Dentro del cómputo de las bajas que traspasan el límite autonómico, la emigración de castellanos y leoneses hacia el exterior representa ahora un porcentaje mayor respecto al total de las salidas, poco más del $10 \%$, pero continúa siendo minoritaria en comparación a los movimientos interregionales. La emigración diferencial por sexo también ha crecido a lo largo del periodo estudiado: las mujeres se marchan antes y en mayor proporción que los varones, pues presentan un nivel educativo más alto y, por consiguiente, una mayor movilidad. Al citado aumento de la emigración entre la población autóctona, habría que añadir el saldo migratorio de los extranjeros, que es negativo desde 2012 -más tardío en la CC. AA. de menor crecimiento demográfico-.

En cuanto al cambio en el perfil de los emigrados, se puede afirmar que hay una presencia abrumadora de individuos provenientes de las capitales de provincia y de otras ciudades de la región, tanto en términos absolutos como de manera relativa a la población residente; mientras que los antiguos emigrantes, los del Desarrollismo, procedían casi en su totalidad del agro castellano. Los actuales flujos de salida del medio rural se canalizan mayoritariamente hacia las capitales provinciales, otras ciudades castellanas y leonesas y los respectivos centros comarcales; y las personas de las capitales y de otros municipios más dinámicos tienen una mayor presencia en los movimientos interregionales y exteriores. Aunque, bien es cierto, que las capitales son utilizadas como puente por algunos castellanos y leoneses de ámbitos territoriales menores.

El perfil educativo y profesional también ha variado notablemente. En el año 2011, más de la mitad de los castellano y leoneses de 25 a 39 años que vivían

85 López-Gay, 2016-b. 
fuera de la región tenían estudios universitarios, frente a poco más del $10 \%$ del mismo grupo etario en el Censo de 1981. El aumento del nivel educativo entre el colectivo emigrado no es solo el resultado de la expansión educativa, sino que el desajuste entre el nivel educativo y el tejido productivo regional ha generado una marcada emigración diferencial de los titulados universitarios en el Censo de 2011 , en comparación a los periodos intercensales precedentes, y un incremento de la selectividad educativa en las migraciones. El porcentaje de personas con estudios de tercer grado en 2011 era del 31,2 \% entre la población sedentaria y del $52,4 \%$ en el caso de los emigrantes. Los castellanos y leoneses residentes en otras CC. AA. han aumentado su representatividad en las categorías profesionales que requieren un nivel de cualificación elevado: una tercera parte de este colectivo se empleaban como técnicos y profesionales científicos e intelectuales y también en otras ocupaciones de "oficina" que precisan una cualificación media. Los trabajos industriales y de construcción, ocupación principal de los antiguos emigrados, han perdido bastante peso - crisis y reconversión industrial-, mientras que los servicios de baja cualificación son variables en el tiempo. Pese a que el perfil profesional ha cambiado drásticamente, se aprecia cierta sobrecualificación en destino, aunque menor que en origen.

Las áreas receptoras también difieren entre las distintas generaciones de emigrantes. Los antiguos flujos de salida se dirigían hacia las ciudades más industrializadas y las localidades donde imperaba el turismo de costa, necesitadas de mano de obra poco cualificada: Madrid, Barcelona, las aglomeraciones urbanas del País Vasco y el litoral de la Comunidad Valenciana. El 40 \% de los actuales emigrantes se concentran en el Área Metropolitana de Madrid, que se consolida como polo de atracción por excelencia. El stock restante se reparte por el territorio español en proporciones reducidas, destacando, por cercanía o dinamismo: Barcelona y su área de influencia, las áreas urbanas de Gijón-Oviedo, Palma de Mallorca, Bilbao, Alicante-Elche o Santander. El País Vasco ha perdido su poder centrípeto y Barcelona, al contrario de lo esperado, parece que ha disminuido su capacidad de atracción hacia Castilla y León. Algunos autores hablan sobre la dispersión de los destinos interregionales ${ }^{86}$, pero no mencionan el creciente poder de atracción de la aglomeración madrileña en el caso de Castilla y León. En cuanto a los patrones de localización urbana, dentro de las ciudades de Madrid y Barcelona se ha podido observar un cambio muy importante en referencia a los distritos donde se concentran los castellanos y leoneses: los antiguos emigrados estaban segregados en los polígonos de vivienda de las barriadas obreras, y en la actualidad las preferencias residenciales se inclinan hacia sectores privilegiados y otros en plena transformación sociodemográfica a favor de los estratos sociales de condición socioeconómica más altos.

En definitiva, las hipótesis planteadas se verifican y los datos apuntan hacia una nueva encrucijada demográfica en la ya despoblada y envejecida Castilla y León. Aparecen dos factores diferenciales respecto a las anteriores etapas emigra86 Olano, 1990; Ródenas, 1994; Recaño, 2004-b y 2006. 
torias: la fuga de talento, entendida como el incremento de la emigración entre los titulados universitarios, y el aumento de la intensidad emigratoria en las ciudades. A pesar de la escasez de activos jóvenes, estos se están marchando de la región en mayor medida que en el último cuarto del siglo XX, especialmente los más formados. El aumento de las bajas en los ámbitos urbanos también es especialmente alarmante. En determinadas áreas rurales poco se puede hacer para revertir las consecuencias de la despoblación, pero parece ser que ahora son los ámbitos urbanos los más afectados por la emigración. En las próximas décadas, si continúa la tendencia observada, las ciudades de Castilla y León podrían perder un número considerable de jóvenes y aumentar los niveles de envejecimiento, dependencia y perjudicar la ya limitada capacidad de crecimiento natural, comprometiendo seriamente la sostenibilidad del territorio castellano y leonés. Esta dinámica se estaría produciendo también en otras regiones españolas con características análogas, como Extremadura, Asturias o Cantabria. Mientras tanto, las regiones receptoras, principalmente las grandes áreas urbanas, se ven beneficiadas por la atracción de personas y talento procedente de las áreas menos dinámicas en un proceso de causación acumulativa, que continuaría incrementando y perpetuando los desequilibrios regionales existentes ${ }^{87}$.

\section{Bibliografía y recursos utilizados}

ANTOLÍN, Pablo y BOVER, Olimpia. Regional migration in Spain: The effect of personal characteristics and of unemployment, wage and house price differentials using pooled cross-sections. Oxford Bulletin of Economics and Statistics, 1997, Vol. 59, n² 2, p. 215-235.

ARANGO, Joaquín. Cambio económico y movimientos migratorios En la España oriental del primer tercio del siglo XX: algunas hipótesis sobre determinantes y consecuencias. Hacienda Pública Española, 1976, 38, p. 51-80.

ARANGO, Joaquín. Las leyes migratorias de E.G. Ravenstein cien años después. Revista Española de Investigaciones Sociológicas, 1985, nº 32, p. 7-26.

ARANGO, Joaquín. España: una experiencia migratoria singular. En TORRES, Cristóbal (ed.) . Madrid: CIS, 2015, p. 268-275.

ARTAL, Andrés; NAVARRO, José Miguel; REQUENA, Francisco. Migraciones interiores en España durante la crisis económica. En AJA, Eliseo; ARANGO, Joaquín; OLIVER, Josep (Eds.) Anuario de la Inmigración en España 2014. Flujos cambiantes, atonía institucional. Barcelona: CIDOB, 2015, p.148-168.

BERNARD, Aude, BELL, Martin. Educational selectivity of internal migrants. Demographic Research, 2018, Vol. 39, n 29, p. 835-854.

BIER, Alice Gail. Tendencias migratorias y características de los migrantes: España, 1967. En ESPINA, Álvaro; FINA, Lluis; LORENTE, Ramón (Eds.) Estudios de economía del trabajo en España I. Oferta y demanda de trabajo. Madrid: Ministerio de Trabajo y Seguridad Social, 1985, p. 325-350.

87 Myrdal, 1957; Massey, 1990; Sassen, 1993. 
BONTJE, Marco; PETHE, Heike; PETRASCH, Frank; TUPPINGER, Katrin. Amsterdam: an attractive creative knowledge region? The view of transnational migrants. Amsterdam: AMIDSt, University of Amsterdam, 2009.

BROWN, Julie and MECZYNSKY, Michael. Complex-cities: Locational Choices of Creative Knowledge Workers. Built Environment, 2009, Vol. 35, no 2, p. 238-252.

BUCH, Tanja; HAMANN, Silke; NIEBUHR, Annekatrin; ROSSEN, Anja. What Makes Cities Attractive? The Determinants of Urban Labour Migration in Germany. Urban Studies, 2014, Vol. 51, no 9.

CABALLERO, Pedro; DELGADO, José María; MARTÍNEZ, Luis Carlos. La evolución demográfica de Castilla y León: una trayectoria que refleja los rasgos y manifiesta las contradicciones del modelo español. En DELGADO, José María (Coord.). Población y poblamiento en Castilla y León. Valladolid: Consejo Económico y Social de Castilla y León, 2012, p. 301-527.

CABRÉ, Anna; MORENO, Julio; PUJADAS, Isabel. Cambio migratorio y reconversión territorial en España. Revista Española de Investigaciones Sociológicas, 1985, nº 32, p. 43-65.

CABRER, Bernadí; SERRANO, Guadalupe; SIMARRO, Rocío. Flujos migratorios y movilidad del capital humano. Investigaciones Regionales, 2009, n 16, p. 5-42.

CÁMARA, Noelia. Los movimientos migratorios internos en la España actual. Estudios Geográficos, 2009, Vol. 70, nº 267, p. 351-385.

DELGADO, José María. Evolución de la población y configuración del modelo de poblamiento en España. En DELGADO, José María (Coord.). Población y poblamiento en Castilla y León. Valladolid: Consejo Económico y Social de Castilla y León, 2012, pp.157-298.

DELGADO, José María; MARTÍNEZ, Luís Carlos. La huella de la inmigración extranjera en las Comunidades Autónomas de menor crecimiento demográfico. Cuadernos Geográficos, 2016-a, Vol. 55, n² 2, p. 127-15.

DELGADO, José María y MARTÍNEZ, Luis Carlos. La situación de la población en Castilla y León. Informe Anual de 2015, Serie Monográfica. Valladolid: Consejo Económico y Social de Catilla y León, 2016-b.

DELGADO, José María y MARTÍNEZ, Luis Carlos. Situación de la población en Castilla y León en 2016. Monográfico de población. Valladolid: Consejo Económico y Social de Catilla y León, 2017.

DEL REY, Alberto y CEBRIÁN, Mar. Un doble proceso de despoblamiento en la España interior durante el siglo XX: migraciones y pérdida de nacimiento en Castilla y León. En LÓPEZ, Lorenzo; ABELLÁN, Antonio; GODENAN, Dirk (Eds.) Envejecimiento, despoblación y territorio: un análisis sobre la población española. León: Universidad de León, 2009, p. 583-594.

DOMINGO, Andreu; BAYONA, Jordi. Inmigració y territori: Concentració i segregació al municipi de Barcelona, 1991-2002. Barcelona Societat, 2004, nº 13, p. 114-128. 
DOMINGO, Andreu; SABATER, Albert. Crisis económica y emigración: la perspectiva demográfica. En AJA, Eliseo; ARANGO, Joaquín; ALONSO, Josep Oliver (Eds.) Anuario de la Inmigración en España 2012. Inmigración y crisis: entre la continuidad y el cambio. Barcelona: CIDOB, 2013, p. 60-87.

DOMINGO, Andreu y BLANES, Amand. Inmigración y emigración en España: estado de la cuestión y perspectivas de futuro. En AJA, Eliseo; ARANGO, Joaquín; ALONSO, Josep Oliver (Eds.) Anuario de la Inmigración en España 2014. Flujos cambiantes, atonia institucional. Barcelona: CIDOB, 2015, p. 91-122.

DOMINGO, Andreu y CABRÉ, Anna. La demografía del siglo XXI. Evolución reciente y elementos prospectivos. En TORRES, Cristóbal (Ed.). España 2015. Situación Social. Madrid: CIS, 2015, p. 63-73.

ERDOZAÍN, Pilar y MIKELARENA, Fernando. Algunas consideraciones acerca de la evolución de la población rural en España en el siglo XIX. Noticiario de Historia Agraria, 1996, nº 12, p. 91-118.

FERIA, José María y SUSINO, Joaquín. La dimensión regional y los nuevos referentes espaciales de las migraciones interiores en España. En FERNÁNDEZ CORDÓN, José Antonio y LEAL MALDONADO, Jesús (Eds.) Análisis territorial de la demografía española. Madrid: Fundación Abril Martorell, 2006, p. 319-359.

FLORENCIO, Antonio y LÓPEZ-MARTÍNEZ, Antonio. Las migraciones estacionales agrarias en Andalucía anteriores al siglo XX. Boletín de la Asociación de Demografía Histórica, 2000, Vol. XVIII, nº 1, p. 71-100.

FLORIDA, Richard. The Rise of the Creative Class and How it's Transforming Work, Leisure, Community and Everyday Life. New York: Basic Books, 2002.

FRANCH, Xavier. La dinámica de las migraciones internas en España: una aproximación demoespacial. Doctoral dissertation, Centre d'Estudis Demogràfics y Departament de Geografia (Universitat Autònoma de Barcelona), Barcelona, Spain, 2009.

GALEANO, Juan Martín. Asentamiento territorial de la población extranjera en España a inicios del siglo XXI: segregación residencial, concentración territorial y diversidad poblacional. Doctoral dissertation, Centre d'Estudis Demogràfics y Departament de Geografia (Universitat Autònoma de Barcelona), Barcelona, Spain, 2016.

GARCÍA BARBANCHO, Alfonso. Las migraciones interiores en España. Estudio cuantitativo desde 1900. Madrid: Estudios de Desarrollo Económico, 1967.

GARCÍA BARBANCHO, Alfonso y DELGADO CABEZA, Manuel. Los movimientos migratorios interregionales en España desde 1960. Papeles de Economía Española, 1988, no 34, p. 240-265.

GARCÍA-COLL, Arlinda; PUYOL, Rafael. Las migraciones interiores en España. En PUYOL, Rafael. (Ed.) La dinámica de la población en España. Madrid: Síntesis, 1997, p. 167-216.

GARCÍA-COLL, Arlinda; STILLWELL, John. Inter-Provincial Migration in Spain: Temporal Trends and Age-Specific Patterns. International Journal of Population Geography, 1999, n5, p. 97-115. 
GARCÍA-COLL, Arlinda; STILLWELL, John. Internal Migration and Regional Population Dynamics in Europe. Spain case study. Working Paper 00/08. University of Leeds, 2000.

GARCÍA-COLL, Arlinda. Migraciones interiores y transformaciones territoriales. Papeles de Economía Española, 2005, no 104, p.76.91.

GARCÍA FERNÁNDEZ, Jesús. El movimiento migratorio de trabajadores en España. Estudios Geográficos, 1964, nº 95, p. 139-174.

GARCÍA FERNÁNDEZ, Jesús. Desarrollo y atonía en Castilla. Barcelona: Ariel, 1981.

GARCÍA ZARZA, Eugenio. La emigración en Castilla y León: causas, características y consecuencias. Valladolid: Consejo General de Castilla y León, 1983.

GONZÁLEZ-FERRER, Amparo. La nueva emigración española. Lo que sabemos y lo que no. Zoom Politico, 2013, Vol. 18.

GONZÁLEZ-LAXE, Fernando; MARTÍN-BERMÚDEZ, Federico; MARTÍN-PALMERO, Federico. Diferencias estructurales, emigración interregional y fuga de cerebros: el caso de Galicia. Revista Galega de Economía, 2013, Vol. 22, nº. 2, p. 9-30.

GONZÁLEZ-LEONARDO, Miguel. El nuevo paradigma de la emigración en Castilla y León: la tercera etapa emigratoria. Master's dissertation, Universitat Autònoma de Barcelona, 2017.

GONZÁLEZ-LEONARDO, Miguel; LÓPEZ-GAY, Antonio. Emigración y fuga de talento en Castilla y León. BAGE. Boletín de la Asociación de Geógrafos Españoles, 2019, 80 (2612), p. 1-29.

GOULD, William T.S. (1982). Education and internal migration: A review and report. International Journal of Educational Development, 1982, Vol. 1, no 3, p. 103-111.

HAMNETT, Chris. Gentrification at the Middle-class. Remarking of Inner London, 1961-2001. Urban Studies, 2003, Vol. 40, n 12, p. 2401-2426.

HANSEN, Hogni and NIEDOMYSL, Thomas. Migration of the creative class: evidence from Sweden, Journal of Economic Geography, 2009, Vol. 9, no 2, p. 191-206

HERRERA-CEBALLOS, María Jesús. Migración cualificada de trabajadores de España al extranjero. En ARANGO, Joaquín; MOYA, David; ALONSO, Josep Oliver (Eds.) Anuario de la Inmigración en España 2013. Inmigración y emigración: mitos y realidades. Barcelona: CIDOB, 2014, p. 90-107.

INSTITUTO NACIONAL DE ESTADÍSTICA. Microdatos de los Censos de Población de 1981, 1991, 2001 y 2011. Facilitados por el Banco de Datos del CED.

INSTITUTO NACIONAL DE ESTADÍSTICA. Microdatos de la Estadística de Variaciones Residenciales, 1988 - 2015. Facilitados por el Banco de Datos del CED.

INSTITUTO NACIONAL DE ESTADÍSTICA. Migraciones exteriores, 1962 - 2001. En Anuarios Estadísticos. Madrid: INE, 1963 - 2002.

INSTITUTO NACIONAL DE ESTADÍSTICA. Migraciones interiores, 1962 - 1987. En Anuarios Estadísticos. Madrid: INE, 1963 a 1988. Facilitados por J. Recaño.

INSTITUTO NACIONAL DE ESTADÍSTICA. Microdatos del Padrón Municipal de Habitantes, 2009 y 2016. Facilitados por el Banco de Datos del CED. 
LEAL, Jesús. Segregación social y mercados de vivienda en las grandes ciudades. Revista Española de Sociología, 2002, n 2, p. 59-75.

LEAL, Jesús y DOMÍNGUEZ, Marta. Transformaciones económicas y segregación social en Madrid. Ciudad y Territorio - Estudios Territoriales, 2008, Vol. 11, nº 158, p. 703-725.

LÓPEZ DE LERA, Diego. Panorama de la migración internacional en España. En TORRES, Cristóbal (Ed.) España 2015. Situación Social. Madrid: CIS, 2015, p. 196-206.

LÓPEZ-GAY, Antonio. Migración, nivel de instrucción y filtro educativo en la ciudad de Barcelona. Paper de Demografía, 2006, nº 296.

LÓPEZ-GAY, Antonio. Canvis residencials y moviments migratoris en la renovaciò poblacional de Barcelona. Doctoral dissertation, Centre d'Estudis Demogràfics y Departament de Geografia (Universitat Autònoma de Barcelona), Barcelona, Spain, 2007.

LÓPEZ-GAY, Antonio. Atracción de talento y polarización socioeconómica en Barcelona. Perspectives Demogràfiques, 2016-a, nº 3.

LÓPEZ-GAY, Antonio. El advenimiento de las regiones metropolitanas maduras en España: retos demográficos y socioeconómicos en un nuevo contexto urbano. Panorama Social, 2016-b, no 23, p. 179-196.

MARTIN-BRELOT, Helene; GROSSETTI, Michael; ECKERT, Denis; GRITSAI, Olga; KOVÁCZ, Zoltán. The Spatial Mobility of the 'Creative Class': A European Perspective. International Journal of Urban and Regional Research, 2010, Vol. 34, nº 4, p. 854-870.

MASSEY, Douglas. Social structure, household strategiesm and the cumulative causation of migration. Population Index, 1990, nº 56, p.3-26.

MENDOZA, Cristóbal; ORTIZ-GUITART, Anna. Hacer las Américas. Migrantes españoles de alta calificación en la ciudad de México. Documents d'Anàlisi Geogràfica, 2006, no 47, p. 93-114.

MIGUELEZ, Ernest and MORENO, Rosina. What attracts knowledge workers: the role of space and social networks. Journal of Regional Science, 2014, Vol. 54, $\mathrm{n}^{0} 1$, p. 33-60.

MINISTERIO DE FOMENTO. Atlas Estadístico de las Áreas Urbanas. Madrid: Ministerio de Fomento, 2016.

MÓDENES, Juan Antonio. Una visión demográfica de la movilidad residencial reciente en España. Papers de Demografía, 2006, no 292.

MÓDENES, Juan Antonio y LÓPEZ-COLAS, Julián. Cambio demográfico reciente y vivienda en España: ¿hacia un nuevo sistema residencial? Revista Española de Investigaciones Sociológicas, 2014, no 148, p. 103-134.

MORENO, Jaime Martín. Aspectos demográficos del fenómeno de la emigración exterior. En ESPINA, Álvaro; FINA, Lluis; LORENTE, Ramón. Estudios de economía del trabajo en España I. Oferta y demanda de trabajo. Madrid: Ministerio de Trabajo y Seguridad Social, 1985, p. 393-419.

MUSTERD, Sako and MURIE, Alan. Making Competitive Cities. Chichester: Wiley-Blackwell, 2010. 
MYRDAL, Gunnar (1957). Rich Lands and Poor. En DEMETRIOS, Papademetriour and PHILIP, Martin (Eds.) The Unsettled Relationship: Labour Migration and Economic Development. New York: Greenwood Press, 1991, p. 3-26.

OLANO, Agustín. Las migraciones interiores en fase de dispersión. Revista de economía y sociología del trabajo, 1990, no 8-9, p. 86-97.

PASCUAL DE SANS, Àngels. Los movimientos migratorios de retorno, significado y perspectivas. , 1983, nº3.

PETHE, Heike and HAFNER, Sabine. Internationalisation and Policies towards Transnational Migration. En MUSTERD, Saco and KOVÁCS, Zoltán. (Eds.) Place-making and Policies for Competitive Cities. Chichester: Wiley-Blackwell, 2013.

PÉREZ DÍAZ, Víctor. Emigración y cambio social: procesos migratorios y vida rural en Castilla. Barcelona: Ariel, 1971.

PÉREZ DÍAZ, Víctor. Estructura Social del campo y éxodo rural. Estudio de un pueblo de Castilla. Madrid: Tecnos, 1972.

PORTES, Alejandro y and WALTON, John. Labor, Class and the International System. New York: Academic Press, 1981.

PUGA-GONZÁLEZ, María Dolores y ABELLÁN-GARCÍA, Antonio. Los primeros movimientos migratorios en la biografía de los españoles. Estudios Geográficos, 1998, no 59, p. 689-709.

PUJADAS, Isabel y GARCÍA-COLL, Arlinda (1995). Migraciones interiores en España: tendencias recientes y perspectivas de futuro. Revista de Geografía, 1995, Vol. 29, n 3, 150 págs.

RAPADO, José Ramón. Migraciones regionales y evolución de la ocupación en España. En ESPINA, Álvaro; FINA, Lluis; LORENTE, Ramón (Eds.) Estudios de economía del trabajo en España I. Oferta y demanda de trabajo. Madrid: Ministerio de Trabajo y Seguridad Social, 1985, p. 369-392.

RECAÑO, Joaquín y CABRÉ, Anna. Migraciones interregionales y ciclos económicos en España (1988-2001). , 2003, nº 37, p.179-197.

RECAÑO, Joaquín. Las migraciones internas de retorno en España durante la primera mitad de la década de los noventa: implicaciones demográficas y territoriales. , 2004-a, no 243.

RECAÑO, Joaquín. Migraciones internas y distribución espacial de la población española. En LEAL, Jesús (ed.) . Madrid: Fundación Fernando Abril Martorell, 2004-b, p. 187-228.

RECAÑO, Joaquín. Los intercambios poblacionales entre las regiones españolas. En FERNÁNDEZ CORDÓN, José Antonio y LEAL, Jesús (Eds.) Análisis territorial de la demografía española. Madrid: Fundación Abril Martorell, 2006, p. 273-318.

RECAÑO, Joaquín. Factores sociodemográficos y territoriales de las migraciones internas en España: 1971 - 2011. XIV Congreso Nacional de Población. Sevilla, AGE, 2014.

RECAÑO, Joaquín. Familia, género y migración interna en España. Revista de Demografía Histórica, 2015-a, Vol. 33, no 2, p. 153-184. 
RECAÑO, Joaquín. Migraciones. En España 2015. En TORRES, Cristóbal. España 2015-. Situación Social. Madrid: CIS, 2015-b, p. 74-84.

RECAÑO, Joaquín. La consolidación de las migraciones internas de inmigrantes como factor estructural de la movilidad geográfica de España. Panorama Social, 2016, n² 24, p. 49-71.

REHER, David. Town and Country in Pre-industrial Spain, Cuenca, 1550-1870, Cambridge: Cambridge University Press, 1990.

REHER, David y REQUENA, Miguel. ¿España en la encrucijada? Consideraciones sobre el cambio de ciclo migratorio. , 2011, $\mathrm{n}^{\circ}$ 1, p. 9-44.

RÓDENAS, Carmen. Migraciones interregionales en España (1960-1989): cambios y barreras. Revista de Economía Aplicada, 1994, Vol. 2, nº 4, p. 5-36.

RÓDENAS, Carmen y MARTÍ-SEMPERE, Mónica. ¿Son bajos los flujos migratorios en España? Revista de Economía Aplicada, 1997, Vol. 5, n 15), p. 155-171.

RÓDENAS, Carmen y MARTÍ-SEMPERE, Mónica. Migraciones 1990-1999: ¿qué ha sucedido en la última década? Revista Valenciana de Economía y Hacienda, 2002, Vol. 3, n ${ }^{\circ}$ 6, p. 37-58.

RÓDENAS, Carmen y MARTÍ-SEMPRE, Mónica. El nuevo mapa de las migraciones interiores en España: los cambios en el patrón de los sesenta. Investigaciones Regionales, 2005, nº 6, p. 21-40.

RUBIO-CASTILLO, Ana María. La emigración de los jóvenes españoles en el contexto de la crisis. Análisis de datos de un fenómeno difícil de cuantificar. , 2014, nº 1 , p. 101-105.

SJAASTAD, Larry A. The costs and returns of human migration. The Journal of Political Economy, 1962, Vol 70, no 5, p. 80-93.

SASSEN, Saskia. La movilidad del trabajo y del capital: un estudio sobre la corriente internacional de la inversión y del trabajo. Madrid: Ministerio de Trabajo y Seguridad Social, 1993.

SILVESTRE, Javier. Aproximaciones teóricas a los movimientos migratorios contemporáneos: un estado de la cuestión. Historia Agraria, 2000, n 21, p. 157-19.

SILVESTRE, Javier. Las emigraciones interiores en España durante los siglos XX y XXI: una revisión bibliográfica. Revista de Estudios sobre Despoblación y Desarrollo Rural, 2002, Vol. 2, nº 8, p. 227-248.

SLEUTJES, Bart and ROTERMAN, Willem. Urban Regions in the Delta. Stated preferences of international knowledge workers in The Netherlands. Amsterdam: University of Amsterdam, 2014.

SPAIN, Daphne. Why higher-income households move to central cities. Journal of Urban Affairs, 1989, Vol. 11, nº 3, p. 283-299.

TATJER, Mercè. L'evolució de la població de Barcelona entre el 1860 i el 1897. En SOBREQUÉS, Jaume. (ed.) Història de Barcelona. Barcelona: Enciclopèdia Catalana, 1995, Vol. VI, p. 119-150.

VIDAL, Tomàs. Èxode rural y problemática demoespacial a Catalunya (1860-1970). Estudis d' Història Agrária, 1979, no 2, p. 193-204. 
WALLERSTEIN, Immanuel. El moderno sistema mundial. La agricultura capitalista y los orígenes de la economía-mundo europea en el siglo XVI, Madrid: Siglo XXI, 1974. ZIPF, George Kingley. The PIP2/D Hypothesis: On the Intercity Movement of Persons. American Sociological Review, 1946, $\mathrm{n}^{0}$ 11, p. 677-686.

(c) Copyright: Miguel González-Leonardo, Antonio López-Gay, 2019

(c) Copyright: Scripta Nova, 2019

Ficha bibliográfica:

GONZÁLEZ-LEONARDO, Miguel; LÓPEZ-GAY, Antonio; El nuevo paradigma de las migraciones internas en España: mayor movilidad y cualificación. El caso de Castilla y León, Scripta Nova. Revista Electrónica de Geografía y Ciencias Sociales. Barcelona: Universitat de Barcelona, 1 de marzo de 2019, vol. XXIII, nº 609. [ISSN: 1138-97] 